\title{
Effect of curd washing on the properties of reduced-calcium and standard-calcium Cheddar cheese
}

\author{
Jia Hou, ${ }^{*}$ Paul L. H. McSweeney, $†$ Thomas P. Beresford, ${ }^{*}$ and Timothy P. Guinee ${ }^{* 1}$ \\ *Teagasc Food Research Center, Moorepark, Fermoy, Co. Cork, Ireland \\ †School of Food and Nutritional Sciences, University College, Cork, Ireland
}

\begin{abstract}
Washed (W) and nonwashed (NW) variants of standard $(\mathrm{SCa})$ and reduced-calcium ( $\mathrm{RCa}$ ) Cheddar cheeses were made in triplicate, ripened for a $270-\mathrm{d}$ period, and analyzed for composition and changes during maturation. Curd washing was applied to cheeses to give a target level of lactose plus lactic acid in cheese moisture of $3.9 \mathrm{~g} / 100 \mathrm{~g}$ in the $\mathrm{W}$ cheese, compared with a value of $5.3 \mathrm{~g} / 100 \mathrm{~g}$ of lactose plus lactic acid in cheese moisture in the control NW cheeses. The 4 cheese types were denoted standard calcium nonwashed (SCaNW), standard calcium washed (SCaW), reducedcalcium nonwashed (RCaNW), and reduced-calcium washed $(\mathrm{RCaW})$. The mean calcium level was 760 $\mathrm{mg} / 100 \mathrm{~g}$ in the SCaNW and SCaW and $660 \mathrm{mg} / 100$ $\mathrm{g}$ in the RCaNW and RCaW cheeses. Otherwise the gross composition of all cheeses was similar, each with protein, fat, and moisture levels of $\sim 26,32$, and 36 $\mathrm{g} / 100 \mathrm{~g}$, respectively. Curd washing significantly reduced the mean level of lactic acid in the SCaW cheese and residual lactose in both $\mathrm{SCaW}$ and $\mathrm{RCaW}$ cheeses. The mean $\mathrm{pH}$ of the standard-calcium cheese over the $270-d$ ripening period increased significantly with curd washing and ripening time, in contrast to the reducedcalcium cheese, which was not affected by the latter parameters. Otherwise curd washing had little effect on changes in populations of starter bacteria or nonstarter lactic acid bacteria, proteolysis, rheology, or color of the cheese during ripening. Descriptive sensory analysis at $270 \mathrm{~d}$ indicated that the SCaW cheese had a nuttier, sweeter, less fruity, and less rancid taste than the corresponding SCaNW cheese. In contrast, curd washing was not as effective in discriminating between the RCaW and RCaNW cheeses. The RCaW cheese had a more buttery, caramel odor and flavor, and a more bitter, less sweet, and nutty taste than the SCaW cheese, whereas the RCaNW had a more pungent and less
\end{abstract}

Received February 14, 2014.

Accepted July 7, 2014

${ }^{1}$ Corresponding author: tim.guinee@teagasc.ie fruity flavor, a less fruity odor, a saltier, more-bitter, and less acidic taste, and a more astringent mouthfeel than SCaNW. Washing of curd during manufacture provides a means of reducing the contents of lactic acid and residual lactose, increasing $\mathrm{pH}$, and altering the sensory properties of Cheddar cheese, with the level of these effects being significantly less pronounced as the calcium content was reduced.

Key words: curd washing, calcium, $\mathrm{pH}$, sensory

\section{INTRODUCTION}

Curd washing is practiced in the manufacture of some cheese varieties, for example in brine-salted, Dutch-style cheeses such as Edam, Gouda, and Maasdammer, to control the level of lactose and lactic acid and properties of the final cheeses. In the manufacture of these varieties, salting is undertaken by immersion of the molded cheese curd in brine, typically for 1 to $5 \mathrm{~d}$ deepening on size. As salt diffusion into cheese is slow (Guinee and Sutherland, 2011), the growth of starter bacteria and the fermentation of residual lactose to lactic acid could potentially proceed uninhibited into the inner regions of the cheese before the salt has migrated inwards, leading to an excessively low $\mathrm{pH}$. This, in turn, is conducive to a higher degree of calcium solubilization, higher proteolysis by residual coagulant, and impaired texture, taste, and quality (Lawrence et al., 1986). Such an occurrence is prevented by reducing the level of residual lactose in the cheese curd before salting by diluting the whey during the cooking or stirring phase of manufacture by removal of whey and adding water, a process referred to as curd washing. The proportions of whey removed and water added are varied according to the lactose level in the milk, which varies with stage of lactation (O'Brien et al., 1999). Curd washing is also used in the manufacture of cheeses such as Colby and Monterey, whereby cold water is added to and mixed with the drained curd for a relatively short period (5-15 min) before being drained off (Lee et al., 2011). The main purpose here is to reduce curd temperature, depress syneresis, and modify texture (Fox and Guinee, 2013). The degree and mode (batch or continuous) of 
stirring has been found to significantly influence lactic acid content, cheese $\mathrm{pH}$, and ratio of soluble to micellar calcium phosphate (Lee et al., 2011).

Curd washing is not conventionally applied in the manufacture of Cheddar cheese, which is typically salted by adding dry crystalline salt to the milled curd at $\mathrm{pH} 5.2$ to 5.4 before molding and pressing; dry salting is considered to arrest starter culture growth and greatly slow down the metabolism of residual lactose, thereby preventing the $\mathrm{pH}$ from decreasing excessively. Nevertheless, the lactic acid content and $\mathrm{pH}$ of commercial Cheddar cheese varies significantly (Guinee et al., 2008), probably as a result of the interactive effects of several factors, such as rate of acidification, $\mathrm{pH}$ at set (rennet addition) and whey drainage, $\mathrm{pH}$ at salting, level of lactose in the cheese milk, salt sensitivity of the starter culture, moisture content of the curd, and salt content (Czulak et al., 1969; O'Brien et al., 1999). Hence, washing the curd during the manufacture of Cheddar, by partial removal of whey during cooking and stirring and replacement by water, has been investigated as a means of achieving more consistent levels of lactose and lactic acid and flavor of the final cheese (Shakeel-Ur-Rehman et al., 2004; Upreti and Metzger, 2006a; Hou et al., 2014). In previous studies on the effect of washing on Cheddar cheese (Hou et al., 2012, 2014), it was found that increasing curd washing from 0 to $33 \%$ of milk volume significantly reduced mean levels of total lactate and increased the mean cheese $\mathrm{pH}$ by 0.3 to 0.4 units at ripening times greater than $90 \mathrm{~d}$. Overall, washed-curd cheeses were firmer and less brittle, had lower levels of some volatile compounds, and were less acidic, more buttery, sweeter, saltier, and creamier than nonwashed cheeses. Thus, those reports concluded that curd washing may provide a means of creating Cheddar cheese variants with distinctive properties.

The calcium content of commercial Cheddar cheese varies significantly, as indicated in several surveys of different retail Cheddar brands [673-761 mg/100 g (Fenelon et al., 2000a; Guinee et al., 2000b), 638-778 $\mathrm{mg} / 100 \mathrm{~g}$ (Guinee et al., 2008), and 631-871 mg/100 g [C. McCarthy, P. M. Kelly (Teagasc Food Research Centre Moorepark, Fermoy, Co. Cork, Ireland), M. G. Wilkinson (Department of Life Sciences, University of Limerick, Limerick, Ireland), and T. P. Guinee, unpublished data]; using the data from these 3 studies, involving 88 cheeses, the calcium level in commercial Cheddar was $758 \pm 54 \mathrm{mg} / 100 \mathrm{~g}$. Calcium in cheese contributes to the crosslinking of the paracasein network and, thereby, to its integrity and rigidity (Lawrence et al., 1984; Lucey and Fox, 1993). Hence, the level of total calcium, or more specifically the level of casein-bound calcium, as influenced by cheese $\mathrm{pH}$, has a major ef- fect on cheese texture and functionality (Lawrence et al., 1986; Guinee et al., 2002). The calcium content of cheese is controlled principally by the $\mathrm{pH}$ at set, whey drainage, and, in the case of dry-salted cheeses, the $\mathrm{pH}$ at salting (Lawrence et al., 1984). Lower $\mathrm{pH}$ values at rennet addition lead to greater solubilization of colloidal calcium phosphate during the stirring and cooking of the curd particles in the whey and its removal in the drain whey (Hooydonk et al., 1986; Guinee et al., 2002; Upreti and Metzger, 2006a). Previous research investigated the interactive effects of variations in levels of calcium phosphate, residual lactose plus lactic acid, and salt-in-moisture on the composition Cheddar cheese and changes in proteolysis, levels of water-soluble organic acids, and $\mathrm{pH}$ during ripening (Upreti and Metzger, 2006a, 2007). The level of calcium phosphate in the cheese was varied by altering the $\mathrm{pH}$ of the milk at set $(6.6,6.2)$ and the curd at whey drainage (6.4, 5.7 ), the level of lactose and lactic acid in the curd by the addition of lactose powder or by curd washing using a $\mathrm{pH}$-adjusted solution of calcium and phosphate, and the salt-in-moisture content by different salting rates. Curd washing significantly reduced the lactic acid level in the reduced- calcium phosphate cheese, but not in the high- calcium phosphate cheese over 50 wk of ripening; the $\mathrm{pH}$ of the washed-curd high- and low- calcium phosphate cheeses was $\sim 0.1$ unit higher than the corresponding nonwashed cheeses after 50 wk of ripening. Nevertheless, interpretation of the results is somewhat confounded by compositional differences (moisture, fat, protein, phosphorous) between the washed and nonwashed cheeses. The current study investigates the effect of curd washing on the composition, rheology, volatile compounds, and sensory properties of Cheddar cheeses with different calcium levels, but otherwise similar gross composition; calcium levels (763 and 664 $\mathrm{mg} / 100 \mathrm{~g}$ ) were chosen to reflect those found in retail cheese.

\section{MATERIALS AND METHODS}

\section{Cheese Manufacture and Treatments}

Four different treatment cheeses were manufactured in each of 3 replicate trials undertaken over a 3 -wk period from April 28 to May 12, 2011: standard calcium nonwashed (SCaNW), standard calcium washed (SCaW), reduced-calcium nonwashed $(\mathbf{R C a N W})$, and reduced-calcium washed $(\mathbf{R C a W})$. Raw milk samples were separated and standardized to a proteinto-fat ratio of 0.96 , pasteurized at $72^{\circ} \mathrm{C}$ for $15 \mathrm{~s}$, cooled to $31^{\circ} \mathrm{C}$, and pumped to the cheese vats $(500 \mathrm{~L})$. The manufacture of the SCaNW cheeses involved inoculation of cheese milk with a commercial direct vat starter 
(DVS) culture, R-704 (50 U), comprising a mixture of Lactococcus lactis ssp. cremoris and lactis strains (Chr. Hansen Ireland Ltd., Little Island, Co. Cork, Ireland). Thirty minutes later, rennet (Chymax Plus, Chr. Hansen Ireland Ltd.; 200 IMCU (international milk-clotting units) $/ \mathrm{mL}$ ), diluted 1:10 in deionized water, was added at a level of $0.18 \mathrm{~mL} / \mathrm{kg}$ based on a protein level of 3.3 $\mathrm{g} / 100 \mathrm{~g}$.

Otherwise, the cheese-making procedure described by Hou et al. (2012) was used for the manufacture of all cheeses, apart from differences in set $\mathrm{pH}$, drainage $\mathrm{pH}$, and in extent of curd washing between the treatment cheeses. In the case of the washed SCaW cheese, agitation was stopped at $34^{\circ} \mathrm{C}$ and a portion of whey ( $28.8 \%$ of cheese milk) was withdrawn from the cheese vat and replaced by equal weight of pasteurized deionized water at $35^{\circ} \mathrm{C}$. The level of washing (whey removal and replacement with water) was chosen to give a target level of lactose plus lactic acid in cheese moisture (LLAMc) of $3.9 \mathrm{~g} / 100 \mathrm{~g}$ compared with $5.3 \mathrm{~g} / 100 \mathrm{~g}$ for cheese moisture in the nonwashed cheese respectively. Following water addition, the curd-whey mixture was further cooked to $38.5^{\circ} \mathrm{C}$. The whey (SCaNW curd) or diluted whey (SCaW curd) was drained from the curd mass when the curd $\mathrm{pH}$ reached 6.3. The manufacturing procedure of the $\mathrm{RCaNW}$ and $\mathrm{RCaW}$ cheeses were similar to that of the corresponding SCaNW and $\mathrm{SCaW}$ cheeses, apart from the following changes. The pasteurized milk was cooled to $20^{\circ} \mathrm{C}$ to minimize risk of localized acid-induced coagulation on subsequent preacidification to $\mathrm{pH} 6.30$ using $10 \%$ (wt/vol) lactic acid solution; the $\mathrm{pH}$-adjusted milk was then reheated to $31^{\circ} \mathrm{C}$. The $\mathrm{pH}$ values of the milk at set and curd at whey drainage were 6.3 and 5.85 , respectively.

\section{Sampling of Cheese}

Treatment cheeses (20-kg blocks) were sampled at different times $(1,14,30,90,180$, and $270 \mathrm{~d})$ over the 270-d ripening period. On each sampling occasion, a vertical slice $(0.5-\mathrm{cm}$ thick) was removed from one of the vertical outside faces of the block and discarded, and a slab $(\sim 8-\mathrm{cm}$ thick, $\sim 2-\mathrm{kg})$ including the freshly exposed surface was taken for analysis of composition (d 14), texture, proteolysis, color, volatile compounds (d 270), and descriptive sensory analysis (d 270). Following sampling, cheeses were analyzed within $48 \mathrm{~h}$, except in the case of volatiles and descriptive sensory analysis, where rectangular samples of $\sim 100$ and 300 $\mathrm{g}$, respectively, were individually sealed in foil, placed in plastic bags, vacuum wrapped (model $\mathrm{C} 10 \mathrm{H}$, Webomatic, Bochum, Germany), and stored at $-20^{\circ} \mathrm{C}$ for $\sim 30$ to $35 \mathrm{~d}$ before analysis.

\section{Composition Analysis of Cheese}

Curd and whey samples were analyzed for moisture using standard International Dairy Federation methods (Guinee et al., 2000a) and lactose and lactate as described herein. Grated cheese samples were analyzed at $14 \mathrm{~d}$ for protein, fat, $\mathrm{NaCl}$, moisture, ash, $\mathrm{Ca}$, and $\mathrm{P}$ using standard International Dairy Federation methods (Guinee et al., 2000a). The pH was measured after each sampling date on cheese slurry prepared from $20 \mathrm{~g}$ of grated cheese and $12 \mathrm{~g}$ of distilled water (Guinee et al., 2000a).

\section{Microbial Counts in Cheese}

Cheeses were analyzed for counts of starter lactococci and nonstarter lactic acid bacteria (NSLAB) on LM17 and Lactobacillus Selection agar, respectively, as described previously (Hou et al., 2012). Coliforms were enumerated by pour-plating on violet red bile agar incubated at $30^{\circ} \mathrm{C}$ for $24 \mathrm{~h}$, and enterococci were plated on kanamycin-esculin-azide agar at $27^{\circ} \mathrm{C}$ for $24 \mathrm{~h}$.

\section{Sugars and Lactates in Cheese}

Portions (5 g) of finely grated cheese samples were stored in a stomacher bag (Grade Packaging Ltd., Coalville, UK) at $-20^{\circ} \mathrm{C}$ until analyzed, thawed at $4{ }^{\circ} \mathrm{C}$, and analyzed for lactose, glucose, and galactose. The sugars were extracted and measured using the HPLC method described by Zeppa et al. (2001), apart from a modification in the equipment used and flow rate. Lactose, glucose, and galactose were separated and eluted on a $300 \times 7.8 \mathrm{~mm}$ Aminex HPX-87C cation exchange carbohydrate column (Bio-Rad Laboratories, Richmond, CA) and detected with a Waters 2414 Refractive Index Detector (Waters, Bray, Ireland). Sample temperature was set to $12^{\circ} \mathrm{C}$ and the column oven temperature of the HPLC unit was at $60^{\circ} \mathrm{C}$. The mobile phase was $0.009 \mathrm{~N}$ sulfuric acid at a flow rate of $0.5 \mathrm{~mL} / \mathrm{min}$. Standards solutions of lactose, glucose (VWR International Ltd., Dublin, Ireland), and galactose (Sigma-Aldrich Ireland Ltd., Arklow, Ireland) were prepared by dissolving each at a level of $1 \mathrm{mg} /$ $\mathrm{mL}$ in Milli-Q water $(18.2 \mathrm{M} \Omega \mathrm{cm}$; Millipore Ireland B.V., Tullagreen, Carrigtwohill, County Cork, Ireland). Each solution was then further diluted to give reduced and high concentration standards of 10 and $100 \mathrm{mg} / \mathrm{L}$, respectively. These solutions were used to calibrate the concentration against peak height and the retention times for the individual sugars. The concentrations of sugars in the cheeses were calculated by comparing the peak area of samples to standard curves. Sugar con- 
centrations were calculated as grams per 100 grams of cheese.

Similarly, D(-)- and L(+)-lactate were extracted by the previously mentioned procedure and separated on a Phenomenex Chirex 3126 cation exchange silica column (Phenomenex, Macclesfield, UK) fitted with a Waters 2487 Dual $\lambda$ Absorbance Detector (Waters). The mobile phase was $0.001 M$ copper sulfate at a flow rate of $1.0 \mathrm{~mL} / \mathrm{min}$. The concentration of total lactate was calculated as the sum of $\mathrm{D}(-)$ - and $\mathrm{L}(+)$-lactates, and total sugars as the sum of lactose, galactose, glucose, and total lactate. Each analysis was carried out in duplicate.

\section{Proteolysis}

The level of $\mathrm{pH} 4.6$-soluble nitrogen (pH4.6-SN) and levels of $5 \%$ phosphotungstic acid-soluble cheese nitrogen (PTA-SN) were measured, as described previously (Hou et al., 2014). The levels of individual free amino acids (FAA) in the pH4.6-SN extract were determined by using a Beckman 6300 High Performance Analyzer (Beckman Instruments Ltd., High Wycombe, UK), as described by Fenelon et al., (2000a).

\section{Rheology}

Six cheeses cubes $\left(25-\mathrm{mm}^{3}\right.$ cubes) were cut from each treatment cheese using a Cheese Blocker (Bos Kaasgreedschap, Bodengraven, the Netherlands), wrapped in tin foil, and stored at $8^{\circ} \mathrm{C}$ overnight before analysis. Each cube was compressed by $70 \%$ on a texture analyzer (model TA-HDI, Stable Micro Systems, Godalming, UK) with a 5-mm compression plate and a 100-kg load cell, as described previously (Hou et al., 2014). The following rheological parameters were calculated from the resultant force or displacement curves: fracture stress $(\mathrm{kPa})$, the stress at fracture as indicated by the inflection point of the curve; fracture strain, the fractional displacement at fracture; and firmness, the force required to compress the cheese to $30 \%$ of its original height.

\section{Cheese Color Analysis}

The color characteristics of the cheeses were evaluated after 30, 90, 180, and $270 \mathrm{~d}$ of ripening. On each occasion, a 500-g block was cut from each cheese and evaluated for color at 6 different locations across the freshly cut face using a colorimeter (CR-400 Chroma Meter, Konica Minolta, Osaka, Japan) with a condition of illuminant D65 and a $2^{\circ}$ observer. The measurements from the colorimeter test were color space coordinates, namely, $\mathrm{L}^{*}$-value (an index of whiteness), $\mathrm{a}^{*}$-value (an index of redness), and $\mathrm{b}^{*}$-value (an index of yellowness). Prior to measurement, the colorimeter was calibrated using the white Konica Minolta Calibration Plate for the following color space parameters $Y, y$, and $\mathrm{x}$, as defined by the International Commission on Illumination.

\section{Volatile Compounds}

The 270-d-old cheeses were analyzed in triplicate for volatile compounds. For each cheese, a 5-g sample was added to a $20-\mathrm{mL}$ solid phase microextraction vial (Apex Scientific Ltd., Maynooth, Co. Kildare, Ireland) and analyzed by solid phase microextraction coupled to a GC-MS. The samples were transferred from the sample holder to the incubation unit of the GC using a CTC Analytics CombiPal Autosampler (CTC Analytics AG, Zwingen, Switzerland) and equilibrated at $40^{\circ} \mathrm{C}$ for 5 min with agitation. The single $1 \mathrm{~cm} \times 50 / 30 \mu \mathrm{m}$ StableFlex divinylbenzene/Carboxen/polydimethylsiloxane fiber (Supelco, Bellefonte, PA) was exposed to the headspace above the samples for $20 \mathrm{~min}$, retracted, and automatically injected into the GC inlet at $250^{\circ} \mathrm{C}$ and desorbed for $2 \mathrm{~min}$. Volatile compounds were separated using gas-liquid chromatography using conditions defined by (Hannon et al., 2007). The detector used was a Varian 320 triple quad mass spectrometer (Varian Analytical Instruments, Little Island, Cork, Ireland) performed by electron impact at $70 \mathrm{eV}$.

\section{Descriptive Sensory Analysis}

The sensory properties of the 270-d-old cheeses from each of the 3 replicate trials were evaluated using descriptive sensory analysis, as described previously (Hou et al., 2014). Duplicate samples ( $300-\mathrm{g}$ blocks) were taken from each cheese and stored at $-20^{\circ} \mathrm{C}$ until required for analysis; samples were thawed by holding overnight at $4^{\circ} \mathrm{C}$. A trained panel, comprising 13 experts who routinely perform sensory analysis on Cheddar cheeses, assessed the cheese for 7 odor, 9 flavor, and 5 taste attributes. The sensory scores awarded to each of the treatment cheeses from any one trial by the individual assessors were averaged; the means for the triplicate trials were obtained from these averages. The mean scores for the different sensory attributes were standardized (1/SD of the mean score for each attribute) and analyzed using principal component analysis (PCA) by Unscrambler V 6.1 (Camo AS, Trondheim, Norway). The results are presented as a principal component (PC) plot. Attributes scored for odor included pungent, sweaty or cheesy, rancid, fruity, buttery, caramel, and estery; attributes for flavor were pungent, rancid, fruity, buttery, caramel, waxy, sweaty 
or cheesy, nutty, and onion; those for taste comprised sweet acid, salt bitter, and astringent.

\section{Statistical Analysis}

Three replicate cheese-making trials (blocks) were undertaken, each with 4 treatment cheeses, namely SCaNW, SCaW, RCaNW, and RCaW. The ANOVA was used to determine if the treatment cheeses differed with respect to response variables, such as compositional factors, at specific time points (e.g., 14 d). Analysis of variance was undertaken using SAS version 9.1.2 (SAS Institute, 2004), where the effects of treatment (curd washing or calcium reduction) and replicates were estimated for all response variables. Tukey's multiple-comparison test was used for paired comparison of treatment means and the level of significance was determined at $P<0.05$.

The data for changes in individual response variables (such as sugars and proteolysis) in the standard-calcium (SCa) and reduced-calcium ( $\mathbf{R C a}$ ) cheeses as a function of ripening were analyzed using a split-plot design to determine the effects of treatment, ripening time, and their interaction. The ANOVA for the split-plot design was carried out using a general linear model procedure of SAS (SAS Institute, 2004), and significance at $P<0.05$ determined using Fisher's least significant difference test. The data for volatile compounds and descriptive sensory analysis, measured at d 270 only, were analyzed using PCA and showed on the PC plot.

\section{RESULTS AND DISCUSSION}

\section{Composition at 14 Days}

The gross composition of all cheeses complied with that for Cheddar cheese as specified by legislation (Table 1; CFR, 2008). Washing significantly reduced the levels of lactose, total lactate, total sugars, and lactateto-protein ratio, and increased the $\mathrm{pH}$ and fat in $\mathrm{DM}$ in the SCa cheeses at $14 \mathrm{~d}$. The reduction in the concentrations of lactose and lactate is consistent with the results of previous studies (Shakeel-Ur-Rehman et al., 2004; Hou et al., 2012). In contrast to the SCa cheeses, washing did not significantly affect the concentrations of lactose, total lactate, or lactate-to-protein ratio in the RCa cheeses. Reducing the calcium content did not affect the gross composition or $\mathrm{pH}$ of the 14-d-old nonwashed or washed cheeses (Table 1). Nevertheless, it is noteworthy that the levels of salt and salt-in-moisture in the RCa cheeses (RCaNW, RCaW) were nonsignificantly higher than those in the corresponding SCa cheeses (SCaNW, SCaW), despite the curds being salted at the same rate and at the same $\mathrm{pH}$. It is feasible that reducing the calcum content of the curd at salting leads to more extensive development of curd fibers (Guinee, 2003), a structural change that increases the level of salt absorbed during mellowing (Gilles, 1976).

The mean calcium content of the SCa cheeses was significantly higher than that of the RCa cheeses. This trend concurs with previous studies showing reduction of $\mathrm{pH}$ at set and at whey drainage as effective means of reducing the calcium content of cheese (Czulak et al., 1969; Guinee et al., 2002). In contrast, the phosphate content of both SCa and RCa cheeses did not differ significantly. This indicates that the reduction in $\mathrm{pH}$ at whey drainage leads to more extensive loss of calcium than phosphorous from curd particles to whey. The higher loss of calcium at the lower whey drainage $\mathrm{pH}$ concurs with the results of Czulak et al. (1969), who concluded that when high acidity in the curd is reached quickly, sufficient calcium is lost to alter the texture properties of the cheese, but insufficient phosphorous is lost to significantly alter the buffering capacity. Those authors suggested that this was due to a greater mobility of the calcium ion than the phosphate ion. A similar observation was made by Upreti and Metzger, (2006a), who reported that the reduction in calcium content on reducing set $\mathrm{pH}$ (6.6 to 6.2) and drain $\mathrm{pH}$ (from 6.2 to 5.7) was much higher than the corresponding reduction in phosphate content; the authors attributed this to a lower degree of solubilization of micellar phosphate. Much of the micellar phosphate $(\sim 40 \%)$ is organic $\mathrm{P}$ (serine phosphate) that is covalently linked to the casein and remains with the casein on $\mathrm{pH}$ reduction (White and Davies, 1958); in contrast, all the micellar calcium is inorganic calcium, attached electrostatically to the casein and solubilized as the $\mathrm{pH}$ is reduced.

\section{Changes in Sugars During Ripening}

Lactose and Total Lactate. Curd washing significantly reduced the mean lactose concentration over the 270-d ripening period in the $\mathrm{SCaW}$ and $\mathrm{RCaW}$ cheeses (Figure 1). This trend concurs with the findings of previous studies (Upreti and Metzger, 2006a; Hou et al., 2012).

The mean level of residual lactose decreased in all cheeses with maturation time (Figure 1; Table 2), coinciding with a concomitant increase in the concentration of lactate (Figure 2). Whereas virtually all lactose had disappeared in the $\mathrm{SCaNW}, \mathrm{SCaW}$, and $\mathrm{RCaW}$ cheeses at $90 \mathrm{~d}, \sim 0.1$ to $0.2 \%$ remained in the RCaNW cheeses after 90, 180, and $270 \mathrm{~d}$ of ripening. Analysis of variance of the data at these times indicated no significant difference between the lactose content of SCaNW and RCaNW or SCaW and RCaW at these times (data not shown). Nevertheless, the nonsignificant higher level of 


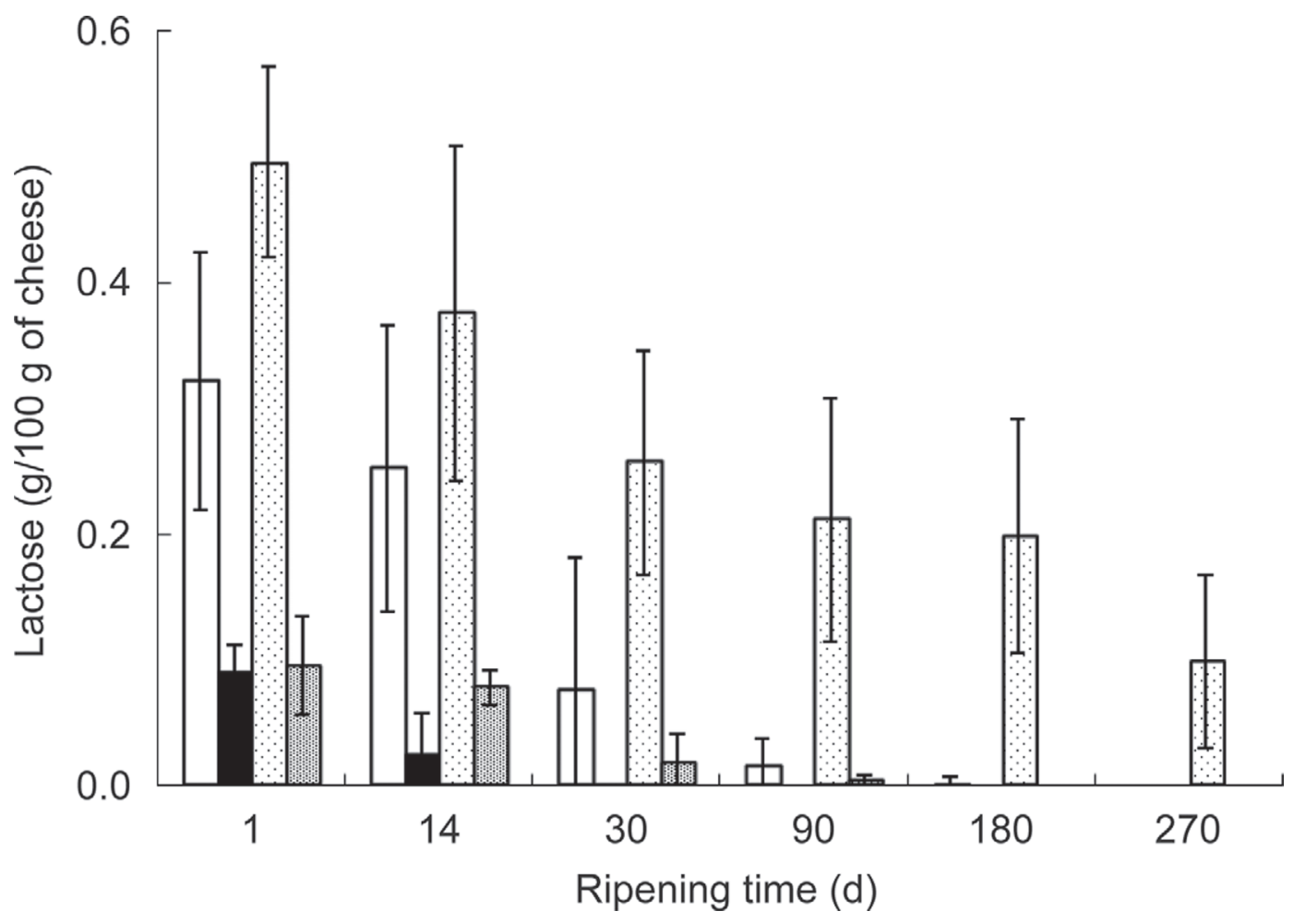

Figure 1. Changes in the levels of residual lactose in control, nonwashed curd cheese with standard (SCaNW, white bar) or reduced-calcium (RCaNW, dotted bar) content, and washed-curd cheese with standard (SCaW, black bar) or reduced-calcium (RCaW, gray bar) content. Presented values are the means of 3 replicate trials; error bars represent standard deviations of the mean.

Table 1. The composition of 14 d-old, nonwashed and washed-curd Cheddar cheeses with standard- or reduced-calcium levels ${ }^{1,2}$

\begin{tabular}{|c|c|c|c|c|}
\hline Cheese composition $^{3}$ & SCaNW & SCaW & RCaNW & RCaW \\
\hline Moisture (g/100 g) & $36.8^{\mathrm{a}, \mathrm{A}}$ & $36.3^{\mathrm{a}, \mathrm{A}}$ & $35.8^{\mathrm{a}, \mathrm{A}}$ & $36.8^{\mathrm{a}, \mathrm{A}}$ \\
\hline Fat $(\mathrm{g} / 100 \mathrm{~g})$ & $31.8^{\mathrm{a}, \mathrm{A}}$ & $32.4^{\mathrm{a}, \mathrm{A}}$ & $32.6^{\mathrm{a}, \mathrm{A}}$ & $32.1^{\mathrm{a}, \mathrm{A}}$ \\
\hline Protein $(\mathrm{g} / 100 \mathrm{~g})$ & $25.9^{\mathrm{a}, \mathrm{A}}$ & $26.4^{\mathrm{a}, \mathrm{A}}$ & $26.5^{\mathrm{a}, \mathrm{A}}$ & $26.3^{\mathrm{a}, \mathrm{A}}$ \\
\hline Lactose (g/100 g) & $0.29^{\mathrm{a}, \mathrm{A}}$ & $0.02^{\mathrm{b}, \mathrm{A}}$ & $0.50^{\mathrm{a}, \mathrm{A}}$ & $0.26^{\mathrm{a}, \mathrm{A}}$ \\
\hline Total lactate $(\mathrm{g} / 100 \mathrm{~g})$ & $1.13^{\mathrm{a}, \mathrm{A}}$ & $0.91^{\mathrm{b}, \mathrm{A}}$ & $0.88^{\mathrm{a}, \mathrm{A}}$ & $0.84^{\mathrm{a}, \mathrm{A}}$ \\
\hline Lactic acid $+\operatorname{sugar}^{4}(\mathrm{~g} / 100 \mathrm{~g})$ & $1.63^{\mathrm{a}, \mathrm{A}}$ & $1.08^{\mathrm{b}, \mathrm{A}}$ & $1.59^{\mathrm{a}, \mathrm{A}}$ & $1.27^{\mathrm{b}, \mathrm{A}}$ \\
\hline Lactate/protein $(\times 100)$ & $4.37^{\mathrm{a}, \mathrm{A}}$ & $3.44^{\mathrm{b}, \mathrm{A}}$ & $3.33^{\mathrm{a}, \mathrm{A}}$ & $3.19^{\mathrm{a}, \mathrm{A}}$ \\
\hline Salt $(\mathrm{g} / 100 \mathrm{~g})$ & $1.75^{\mathrm{a}, \mathrm{A}}$ & $1.79^{\mathrm{a}, \mathrm{A}}$ & $1.85^{\mathrm{a}, \mathrm{A}}$ & $1.93^{\mathrm{a}, \mathrm{A}}$ \\
\hline Calcium (mg/100 g) & $763^{\mathrm{a}, \mathrm{A}}$ & $763^{\mathrm{a}, \mathrm{A}}$ & $675^{\mathrm{a}, \mathrm{B}}$ & $654^{\mathrm{a}, \mathrm{B}}$ \\
\hline $\mathrm{P}(\mathrm{mg} / 100 \mathrm{~g})$ & $475^{\mathrm{a}, \mathrm{A}}$ & $462^{\mathrm{a}, \mathrm{A}}$ & $454^{\mathrm{a}, \mathrm{A}}$ & $449^{\mathrm{a}, \mathrm{A}}$ \\
\hline Calcium/protein ( $\mathrm{mg} / \mathrm{g}$ of protein) & $29.43^{\mathrm{a}, \mathrm{A}}$ & $28.95^{\mathrm{a}, \mathrm{A}}$ & $25.47^{\mathrm{b}, \mathrm{B}}$ & $24.86^{\mathrm{b}, \mathrm{B}}$ \\
\hline $\mathrm{S} / \mathrm{M}(\mathrm{g} / 100 \mathrm{~g})$ & $4.6^{\mathrm{a}, \mathrm{A}}$ & $4.9^{\mathrm{a}, \mathrm{A}}$ & $5.2^{\mathrm{a}, \mathrm{A}}$ & $5.3^{\mathrm{a}, \mathrm{A}}$ \\
\hline MNFS (g/100 g) & $53.9^{\mathrm{a}, \mathrm{A}}$ & $53.7^{\mathrm{a}, \mathrm{A}}$ & $53.2^{\mathrm{a}, \mathrm{A}}$ & $54.2^{\mathrm{a}, \mathrm{A}}$ \\
\hline FDM $(\mathrm{g} / 100 \mathrm{~g})$ & $50.3^{\mathrm{b}, \mathrm{A}}$ & $50.8^{\mathrm{a}, \mathrm{A}}$ & $50.9^{\mathrm{a}, \mathrm{A}}$ & $50.8^{\mathrm{a}, \mathrm{A}}$ \\
\hline $\mathrm{pH}$ at d14 & $5.24^{\mathrm{b}, \mathrm{A}}$ & $5.35^{\mathrm{a}, \mathrm{A}}$ & $5.23^{\mathrm{a}, \mathrm{A}}$ & $5.34^{\mathrm{a}, \mathrm{A}}$ \\
\hline
\end{tabular}

${ }^{\mathrm{a}, \mathrm{b}}$ Values not sharing a common lowercase superscript differ significantly for the statistical effect of washing on the standard calcium (SCaNW, SCaW) and on the reduced-calcium $(\mathrm{RCaNW}, \mathrm{RCaW})$ cheeses $(P<0.05)$.

${ }^{\mathrm{A}, \mathrm{B}}$ Values not sharing a common uppercase superscript differ significantly for the effect of reducing calcium on the nonwashed (SCaNW, RCaNW) and washed $(\mathrm{SCaW}, \mathrm{RCaW})$ cheeses $(P<0.05)$.

${ }^{1}$ The cheese treatments, described in detail in Materials and Methods, included nonwashed (control) curd cheeses with standard (SCaNW) or reduced calcium (RCaNW) content, and washed-curd cheese with standard (SCaW) or reduced-calcium ( $\mathrm{RCaW})$ content.

${ }^{2}$ ANOVA was used to determine differences between treatments.

${ }^{3} \mathrm{~S} / \mathrm{M}=$ salt in moisture; MNFS = moisture in non-fat substances; FDM $=$ fat in DM.

${ }^{4}$ Sugars comprised lactose, glucose, and galactose; the concentrations of the latter 2 sugars were $\sim 0.21$ and $0.15 \%$ for the standard and reduced calcium cheeses, respectively. 
residual lactose in the $\mathrm{RCaNW}$ cheese compared with the SCaNW cheese may reflect the nonsignificant higher mean level of salt-in-moisture of the former (Table 1). This suggestion is supported by the finding of Thomas and Pearce (1981), which showed that the residual lactose in Cheddar cheese at $14 \mathrm{~d}$ after manufacture increased linearly by $\sim 0.025 \%$ per $0.1 \%$ increase in saltin-moisture in the range 4 to $6 \%$ salt-in-moisture. A similar trend to that in the current study was reported by Upreti and Metzger, (2006a), who attributed the higher residual lactose in $\mathrm{RCa}$ cheeses $(\sim 0.25 \mathrm{~g} / 100 \mathrm{~g}$ compared with $0 \mathrm{~g}$ of lactose/100 $\mathrm{g}$ in the SCa cheeses after $350 \mathrm{~d}$ ) to differences in composition between the cheeses, including the higher moisture content (1.5-2.0 $\mathrm{g} / 100 \mathrm{~g}$ ) of the RCa cheeses. Reducing calcium level in the washed or nonwashed curd cheeses did not significantly influence the gross composition (salt-inmoisture, moisture in nonfat substances, fat in DM, pH at d 14, moisture) of corresponding pairs of washed or nonwashed $\mathrm{SCa}$ and $\mathrm{RCa}$ cheeses in the current study.

$\boldsymbol{D}(-)$ - and $L(+)$-Lactate. Curd washing significantly reduced the mean concentrations of $\mathrm{L}(+)$ - and $\mathrm{D}(-)$-lactate in the SCaW cheeses over the 270 - $\mathrm{d}$ ripening period, but not in the RCaW cheeses (Table 2). The mean levels of $\mathrm{L}(+)$-lactate decreased significantly in all cheeses with ripening time, whereas those of $\mathrm{D}(-)$-lactate increased (data not shown). The changes in the concentrations of $\mathrm{L}(+)$ - and $\mathrm{D}(-)$-lactate occurred most rapidly between 30 and $180 \mathrm{~d}$, after which the concentrations changed little. The racemization of $\mathrm{L}(+)$ - to $\mathrm{D}(-)$-lactate, which is a feature in Cheddar cheese maturation (Jordan and Cogan, 1993; Hou et al., 2012), coincided with an increase in the growth of NSLAB from $\sim 10^{5} \mathrm{cfu} / \mathrm{g}$ at $\mathrm{d} 30$ to $\sim 10^{8} \mathrm{cfu} / \mathrm{g}$ at $\mathrm{d} 270$ (data not shown). The mean concentrations of $\mathrm{D}(-)$ - and $\mathrm{L}(+)$-lactate in the SCaNW and SCaW cheeses over the 270-d ripening period were higher than those in the corresponding $\mathrm{RCaNW}$ and $\mathrm{RCaW}$ cheeses (data not shown), a trend consistent with the higher total lactate and lower residual lactose in the SCaNW and SCaW cheeses.

Glucose and Galactose. The mean concentration of glucose $(0.15 \mathrm{~g} / 100 \mathrm{~g})$ in the SCaNW and RCaNW cheeses over the 270 -d ripening period was significantly higher than that in the corresponding SCaW $(0.12$ $\mathrm{g} / 100 \mathrm{~g}$ ) or $\mathrm{RCaW}(0.1 \mathrm{~g} / 100 \mathrm{~g})$ cheeses (data not shown). Glucose decreased significantly in all cheese during ripening, with the decrease $(0.01-0.04 \mathrm{~g} / 100 \mathrm{~g}$ of cheese) depending on treatment.

The mean concentration of galactose over the $270-\mathrm{d}$ ripening period was very low in all cheese. The levels in SCaNW and RCaNW cheeses were similar, at 0.03 $\mathrm{g} / 100 \mathrm{~g}$, and significantly higher than those in the $\mathrm{SCaW}$ and $\mathrm{RCaW}$ cheeses (which were also identical at $0.02 \mathrm{~g} / 100 \mathrm{~g}$ ). Galactose was absent in the $270-\mathrm{d}-$ old cheese. We have no explanation for the presence of glucose and galactose at these concentrations in the cheese.

pH Changes During Ripening. The mean $\mathrm{pH}$ of the SCaW cheeses increased significantly with curd washing and ripening time; moreover, it was significantly affected by the interaction of curd washing and ripening time, as reflected by the increase in the magnitude of the $\mathrm{pH}$ difference between the $\mathrm{SCaW}$ and $\mathrm{SCaNW}$ cheeses as ripening time progressed (Figure 3; Table 2). The $\mathrm{pH}$ of SCaW increased by $\sim 0.2$ units, from $\sim 5.33$ at d 1 to 5.52 at $d 270$, whereas that of SCaNW decreased significantly by $\sim 0.07$ units, from 5.25 to 5.18 over the same time period. The increase in the $\mathrm{pH}$ of the SCaW cheese during ripening is probably associated with pro-

Table 2. Degrees of freedom and statistical significance ( $P$-values) for changes in lactose, $\mathrm{D}(-)$-lactate, $\mathrm{L}(+)$-lactate, total lactate, and $\mathrm{pH}$ in control (nonwashed) and washed-curd Cheddar cheeses with standard- or reduced-calcium level ${ }^{1,2}$

\begin{tabular}{|c|c|c|c|c|c|c|c|c|c|c|}
\hline Factor & \multicolumn{2}{|c|}{ Lactose } & \multicolumn{2}{|c|}{$\mathrm{D}(-)$-Lactate } & \multicolumn{2}{|c|}{$\mathrm{L}(+)$-Lactate } & \multicolumn{2}{|c|}{ Total lactate } & \multicolumn{2}{|c|}{$\mathrm{pH}$} \\
\hline \multicolumn{11}{|l|}{ Standard calcium } \\
\hline Curd washing & 1 & 0.011 & 1 & 0.025 & 1 & $<0.0001$ & 1 & 0.016 & 1 & $<0.0001$ \\
\hline \multicolumn{11}{|l|}{ Subplot } \\
\hline Time & 5 & $<0.0001$ & 5 & $<0.0001$ & 5 & $<0.0001$ & 5 & $<0.0001$ & 5 & 0.026 \\
\hline \multicolumn{11}{|l|}{ Main plot } \\
\hline Curd washing & 1 & 0.041 & 1 & 0.114 & 1 & 0.142 & 1 & 0.056 & 1 & 0.171 \\
\hline \multicolumn{11}{|l|}{ Subplot } \\
\hline Time & 5 & 0.0006 & 5 & $<0.0001$ & 5 & 0.010 & 5 & 0.0004 & 5 & 0.270 \\
\hline Interaction (curd washing $\times$ time) & 5 & 0.361 & 5 & 0.635 & 5 & 0.637 & 5 & 0.702 & 5 & 0.129 \\
\hline
\end{tabular}




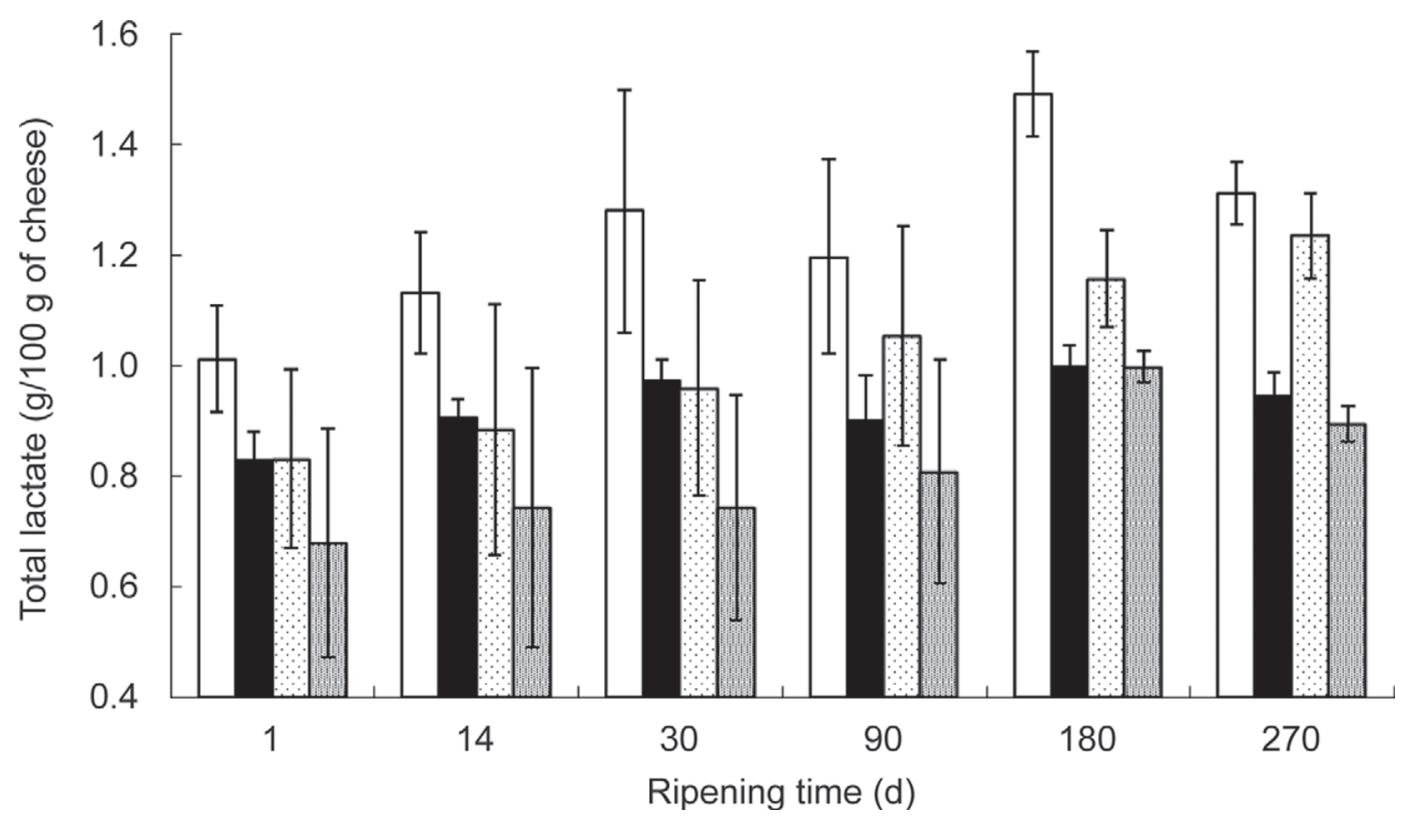

Figure 2. Age-related changes in the level of total lactate in control, nonwashed curd cheese with standard (SCaNW, white bar) or reducedcalcium (RCaNW, dotted bar) content, and washed-curd cheese with standard (SCaW, black bar) or reduced-calcium (RCaW, gray bar) content. Presented values are the means of 3 replicate trials; error bars represent standard deviations of the mean.

teolysis, and the commensurate hydrolysis of peptide bonds resulting in the generation of $-\mathrm{COO}^{-}$and $\mathrm{NH}_{3}{ }^{+}$ in the cheese environment. At the normal lactate concentrations of Cheddar cheese, as in the SCaNW cheese in the current study, the protonation of amino groups does not lead to an increase in $\mathrm{pH}$ because of the excess $\mathrm{H}^{+}$ions from the lactate, which are expected to be fully dissociated in the cheese environment $\left(\mathrm{p} K_{\mathrm{a}} \sim 3.86\right)$. It is noteworthy that the $\mathrm{pH}$ of Gouda, a washed-curd cheese, increases with ripening time, and that for a given washing rate (withdrawal of fixed amount of whey and replacement with equal volume of water) the increase with ripening time is most pronounced when the cheese is made from late lactation milk when the lactose level is likely to be at its lowest (Lawrence et al., 1986). Hence, the divergence between the $\mathrm{pH}$ of the SCaW and SCaNW cheeses probably reflects the lower ratio of lactic acid to buffering substances (protein and phosphate) in the SCaW cheeses (Lucey and Fox, 1993; Salaün et al., 2005).

In contrast to the $\mathrm{SCa}$ cheeses, the mean $\mathrm{pH}$ of the $\mathrm{RCa}$ cheeses over the 270-d ripening period was not significantly affected by curd washing, ripening time, or their interaction. This trend is consistent with that of curd washing, which did not significantly affect the level of total lactate in the RCa cheeses. However, ANOVA at $270 \mathrm{~d}$ indicated that the $\mathrm{pH}$ of the $\mathrm{RCaW}$ cheese was significantly higher than that of the RCaNW cheeses, a result consistent with the lower concentration of total lactate in the former. Similar to the SCaNW cheeses, the $\mathrm{pH}$ of the RCaNW cheese decreased by $\sim 0.05$ units between $\mathrm{d} 1$ and $\mathrm{d} 270$, whereas that of the RCaW cheese increased by $\sim 0.1$ units, from 5.25 at d 1 to 5.35 at $\mathrm{d} 270$.

\section{Microbial Counts of Starter and NSLAB in Cheese}

Starter Bacteria. Starter bacteria counts in all cheeses at d 1 were $\sim 10^{9.5} \mathrm{cfu} / \mathrm{g}$ cheese. The mean starter count of all cheeses decreased significantly with ripening time (data not shown). The magnitude of the decrease in cell count, from $\sim 10^{9.5} \mathrm{cfu} / \mathrm{g}$ at $\mathrm{d} 1$ to $\sim 10^{7.5}$ $\mathrm{cfu} / \mathrm{g}$ at $\mathrm{d} 270$, is typical of that reported elsewhere for Cheddar cheese made using Lactococcus lactis ssp. cremoris and lactis (Turner and Thomas, 1980). In agreement with previous studies on Cheddar (ShakeelUr-Rehman et al., 2004; Hou et al., 2012), the mean starter count in all the cheeses over the 270-d ripening period was not significantly affected by curd washing (data not shown).

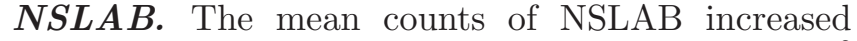
significantly in all cheeses during ripening, from $\sim 10^{2}$ to $10^{3} \mathrm{cfu} / \mathrm{g}$ at $\mathrm{d} 1$ to $\sim 10^{8} \mathrm{cfu} / \mathrm{g}$ at d 270 (data not shown), and were not affected by curd washing. This trend corroborates previous findings, that NSLAB growth in Cheddar was independent of residual lactose content (Turner and Thomas, 1980).

Coliforms and Enterococci. Coliforms and enterococci were present in all cheeses at $1 \mathrm{~d}$, ranging from $10^{3}$ and $10^{3.5} \mathrm{cfu} / \mathrm{g}$ in the nonwashed cheeses to 


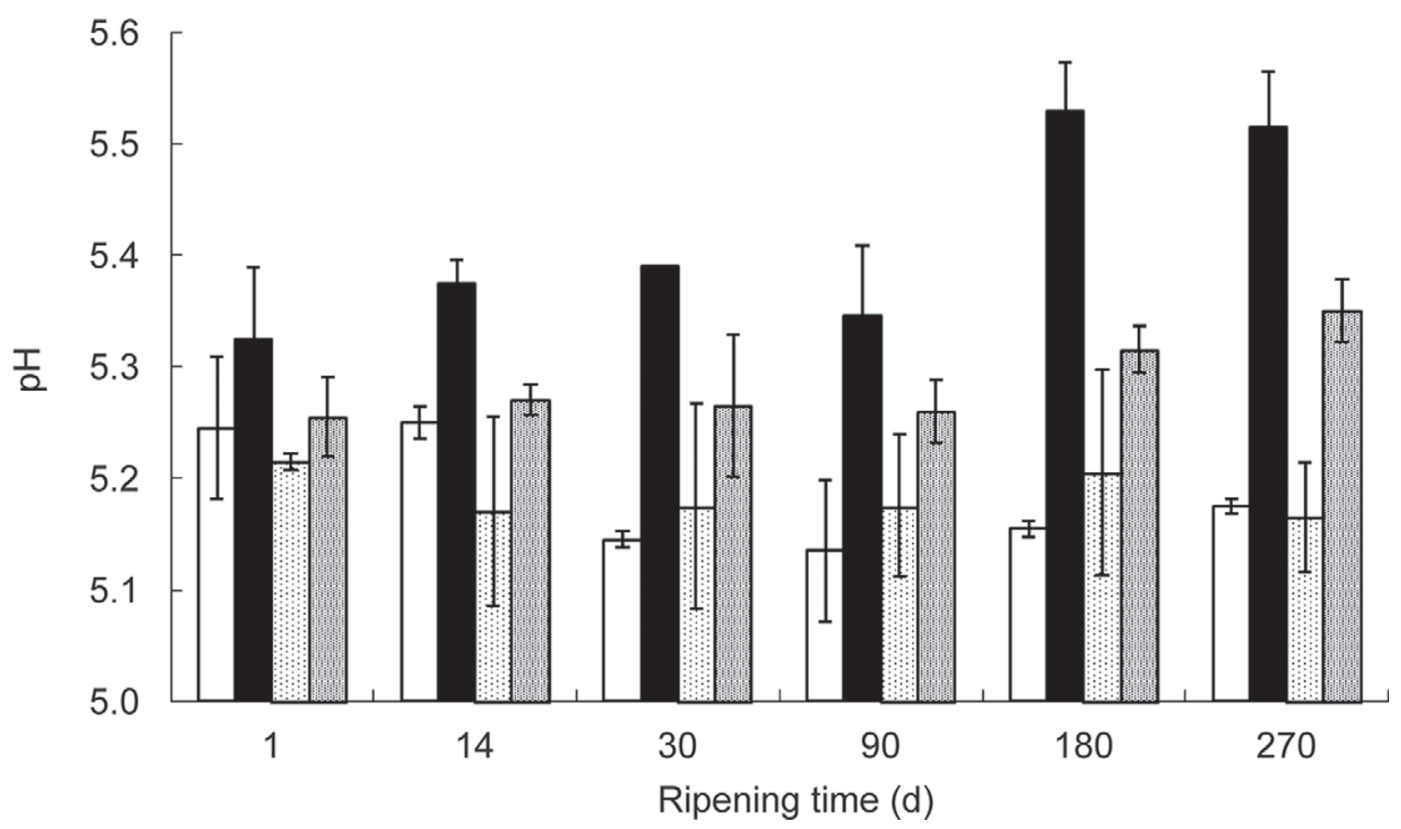

Figure 3. Age-related changes in the $\mathrm{pH}$ in control, nonwashed curd cheese with standard (SCaNW, white bar) or reduced-calcium (RCaNW, dotted bar) content, and washed-curd cheese with standard (SCaW, black bar) or reduced-calcium (RCaW, gray bar) content. Presented values are the means of 3 replicate trials; error bars represent standard deviations of the mean.

$10^{4}$ and $10^{4.5} \mathrm{cfu} / \mathrm{g}$ in the washed curd cheeses, respectively. These organisms decreased rapidly to $<10$ $\mathrm{cfu} / \mathrm{g}$ at $180 \mathrm{~d}$. Coliform bacteria and enterococci are killed by pasteurization and, therefore, their presence in cheese indicates postpasteurization contamination. The relatively high numbers of these bacteria initially present in the cheeses are a reflection of the considerable amount of manual handling of the milk before pilot-scale cheese manufacture. The initial levels in the washed-curd cheeses were generally higher, suggesting that the wash water was also a source of contamination. Rea et al. (2004) investigated the effect of including different strains of Enterococcus (e.g., 3 strains of Enterococcus faecalis and 1 strain each of Enterococcus faecium, Enterococcus durans, and Enterococcus casseliflavus) to a level of $10^{7} \mathrm{cfu} / \mathrm{g}$ in the 1 -d-old cheese and concluded that enterococci had little effect on proteolysis and flavor of Cheddar. Hence, the populations in the current study $\left(<10^{4.5} \mathrm{cfu} / \mathrm{g}\right)$ are unlikely to have had a significant effect on the quality of the cheese. Similarly, it can be concluded from the findings of Kosikowski and Fox (1968) that coliforms at a population of $<10^{5}$ $\mathrm{cfu} / \mathrm{g}$ have no effect on Cheddar cheese flavor.

\section{Proteolysis}

Changes in Primary Proteolysis. The mean level of pH4.6-SN in all cheeses increased significantly over the 270-d ripening period (Figure 4a), but was not af- fected by curd washing. The magnitude of the increase (from $\sim 2.0 \%$ of total $\mathrm{N}$ at $\mathrm{d} 1$ to $\sim 25 \%$ of total $\mathrm{N}$ at d 270 ) is typical of that previously reported for Cheddar cheese matured at $8^{\circ} \mathrm{C}$ (Fenelon et al., 2000a) and is indicative of hydrolysis of the insoluble intact calcium phosphate paracasein into water-soluble peptides by residual chymosin (Fenelon et al., 2000b).

Analysis of variance showed that the RCaNW cheeses had significantly higher levels of pH4.6-SN than the corresponding SCaNW cheeses at 30,90, and $180 \mathrm{~d}$ (data not shown); however, such differences were not observed between the SCaW and RCaW cheeses. A similar trend was reported by Upreti et al. (2006b), who indicated that cheeses with low $\mathrm{Ca}$ and $\mathrm{P}$ had a higher $(P<0.05)$ level of proteolysis than their corresponding high-Ca and $-\mathrm{P}$ treatments, which was due to the higher residual chymosin activity and moisture content in the low $\mathrm{Ca}$ and $\mathrm{P}$ cheeses. Moreover, the higher level of primary proteolysis in the RCaNW cheese at 30, 90, and $180 \mathrm{~d}$ compared with corresponding SCaNW cheese may be associated with a lower degree of calciuminduced interaction and aggregation between the casein molecules, which would increase their susceptibility to chymosin-mediated proteolysis. Hence, O'Keeffe et al. (1975) reported that a reduction in the level of calcium phosphate in Cheddar cheese curd resulted in a significantly higher degree of casein degradation in 1-d-old cheese. Similarly, Fox (1970) reported that the

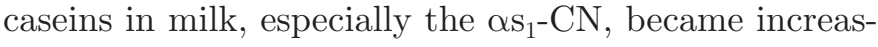



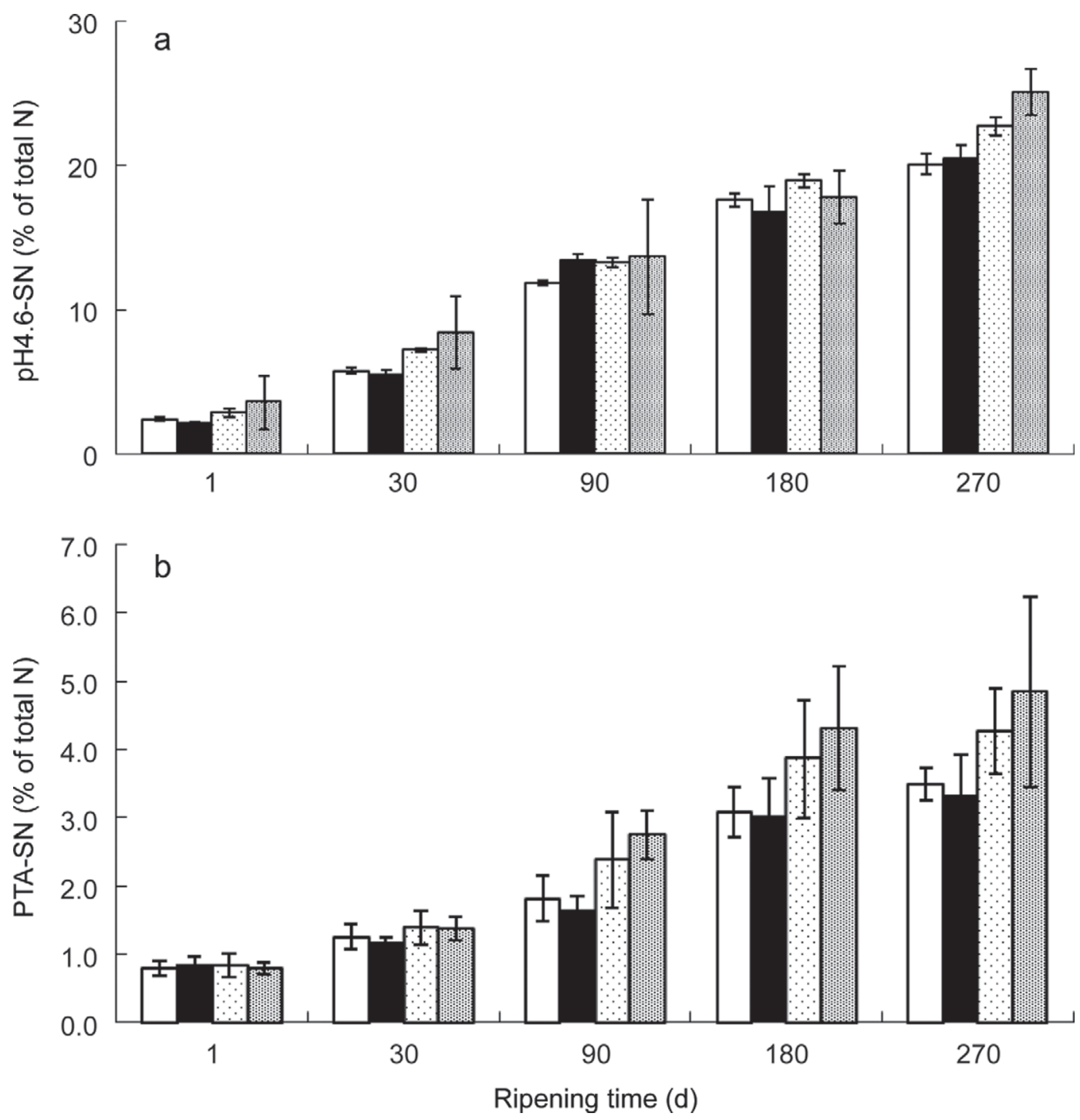

Figure 4. Age-related changes in (a) pH 4.6-soluble nitrogen (pH4.6-SN) and (b) 5\% phosphotungstic acid-soluble cheese nitrogen (PTASN) in control, nonwashed curd cheese with standard (SCaNW, white bar) or reduced-calcium (RCaNW, dotted bar) content, and washed-curd cheese with standard (SCaW, black bar) or reduced-calcium ( $\mathrm{RCaW}$, gray bar) content. Presented values are the means of 3 replicate trials; error bars represent standard deviations of the mean.

ingly susceptible to proteolysis at $\mathrm{pH} 6.6$, as the level of micellar calcium phosphate was reduced; the effect was attributed to the concomitant disruption of the casein micelle structure, increases in the solubility of individual caseins, and their accessibility to rennet. A tentative explanation for the similar levels of proteolysis in the SCaW and RCaW cheeses, in contrast to the SCaNW and RCaNW cheeses, may be the higher mean $\mathrm{pH}$ of the latter cheeses over ripening; it is feasible that the differences associated with calcium level on casein dissociation may not be as pronounced at the higher $\mathrm{pH}$ (5.8-6.4), which would be less conducive to casein hydrolysis (Mulvihill and Fox, 1977).
Changes in Secondary Proteolysis. The PTA-SN and FAA were used as measures of the degree of secondary proteolysis, reflecting the degradation of large molecular weight peptides produced by residual coagulant and plasmin into low molecular weight peptides and FAA (Jarrett et al., 1982; Fenelon et al., 2000b). The mean levels of PTA-SN increased significantly in all cheeses during ripening, but were not affected by curd washing (Figure 4b). A similar trend was found for FAA, the concentrations of which were comparable to those reported for experimental full-fat Cheddar cheeses of similar ages (Fenelon et al., 2000b), but lower than the mean values $(1.0-5.6 \%)$ reported for retail 
Table 3. Degrees of freedom and statistical significances ( $P$-values) for changes in rheology properties in control, nonwashed, and washed-curd Cheddar cheeses with standard- or reduced-calcium levels ${ }^{1,2}$

\begin{tabular}{|c|c|c|c|c|c|c|}
\hline Factor & \multicolumn{2}{|c|}{ Firmness (N) } & \multicolumn{2}{|c|}{ Fracture stress $\left(\mathrm{N} / \mathrm{cm}^{2}\right)$} & \multicolumn{2}{|c|}{ Fracture strain (-) } \\
\hline Curd washing & 1 & 0.078 & 1 & $<0.0001$ & 1 & 0.124 \\
\hline \multicolumn{7}{|l|}{ Subplot } \\
\hline Time & 4 & $<0.0001$ & 4 & $<0.0001$ & 4 & 0.338 \\
\hline \multicolumn{7}{|l|}{ Main plot } \\
\hline Curd washing & 1 & 0.356 & 1 & 0.212 & 1 & 0.847 \\
\hline \multicolumn{7}{|l|}{ Subplot } \\
\hline Time & 4 & $<0.0001$ & 4 & $<0.0001$ & 4 & 0.152 \\
\hline Interaction (curd washing $\times$ time) & 4 & 0.360 & 4 & 0.250 & 4 & 0.060 \\
\hline
\end{tabular}

${ }^{1}$ The cheese treatments, described in detail in Materials and Methods, included control, non-washed curd cheeses with standard (SCaNW) or reduced calcium (RCaNW) content, and washed-curd cheese with standard (SCaW) or reduced-calcium (RCaW) content.

${ }^{2}$ ANOVA was carried using a general linear model (GLM) procedure of SAS, where the effects of treatment, ripening time, and their interaction were estimated.

Cheddar cheeses depending on brand type (Fenelon et al., 2000a; Guinee et al., 2008; data not shown). The FAA content of Cheddar varies with brand type, as influenced by composition, types of culture and cultures adjuncts, and maturation time and temperature.

Comparison of the data at 90 and $180 \mathrm{~d}$ using ANOVA indicated that the levels of PTA-SN/TN in the RCaNW and RCaW were higher than in the corresponding SCaNW and SCaW cheeses (data not shown), despite the similar composition and microbiology of all cheeses. The PTA-N (as a percentage of pH4.6-SN) in the RCaNW and RCaW was also significantly higher (data not shown), suggesting more rapid degradation of the relatively large molecular weight peptides in the pH4.6-SN extract by starter culture peptidases released on autolysis (Fenelon et al., 2000c). A tentative explanation for the relatively high PTA-SN in the RCaNW and RCaW cheeses could be a higher proteolytic activity resulting from a higher degree of autolysis of the nonviable starter cells (Sheehan et al., 2006), or a higher release of starter cell envelope proteinase from starter cells into the cheese matrix (Coolbear et al., 1992; Exterkate and Alting, 1999). Free amino acid $\mathrm{N}$, as a percent of PTA-SN, increased from a mean of $\sim 40 \%$ in all cheeses at $\mathrm{d} 1$ to $\sim 65 \%$ at $\mathrm{d} 270$, and was higher in the $\mathrm{SCaNW}$ and $\mathrm{SCaW}$ cheeses than in the corresponding $\mathrm{RCaNW}$ and $\mathrm{RCaW}$ cheeses (data not shown).

\section{Rheological Properties}

The mean fracture stress and firmness of all cheeses decreased significantly during ripening (Table 3; Figure 5 ; data for firmness not shown). This trend is consistent with the increase in primary proteolysis of the calcium phosphate paracasein network (Figure 4a), which is the main structural component of the cheese matrix resisting the stresses applied during compression (Guinee, 2003). Solubilization of calcium during maturation may be also a contributory factor to ripening-induced softening (O'Mahony et al., 2005).

The mean values for fracture strain and firmness of all cheeses over the 270-d ripening period were not affected by curd washing, a trend which is consistent with the absence of significant differences in the mean levels of pH4.6-SN. However, the mean fracture stress of the SCaW cheese over $270 \mathrm{~d}$ was significantly higher than that of the SCaNW cheese. This may reflect the higher $\mathrm{pH}$ of the SCaW cheese, which would favor a higher level of casein-bound calcium (Lee et al., 2011) and be expected to give a more cohesive, rigid paracasein cheese network that requires higher stress to fracture (Visser, 1991). In contrast, the latter effect was not observed in the RCa cheeses, which may reflect the absence of a significant difference in $\mathrm{pH}$ between $\mathrm{RCaNW}$ and RCaW cheeses.

Though the mean fracture strain of all cheeses over the 270-d ripening period was not influenced by curd washing, ANOVA showed that curd washing significantly reduced the mean fracture strain of both the SCaW and RCaW cheeses at 180 and $270 \mathrm{~d}$ (data not shown). These findings concur with the observations of Visser (1991), who reported that the fracture strain of Gouda cheese as a function of $\mathrm{pH}$ increased to a maximum at $\mathrm{pH}$ values of 5.3 to 5.4 depending on age, and thereafter decreases with further increasing $\mathrm{pH}$. An increase in $\mathrm{pH}$ to values $>5.3$ (as in the $\mathrm{SCaW}$ and $\mathrm{RCaW}$ at times $\geq 180 \mathrm{~d}$ ) is conducive to a higher ratio 


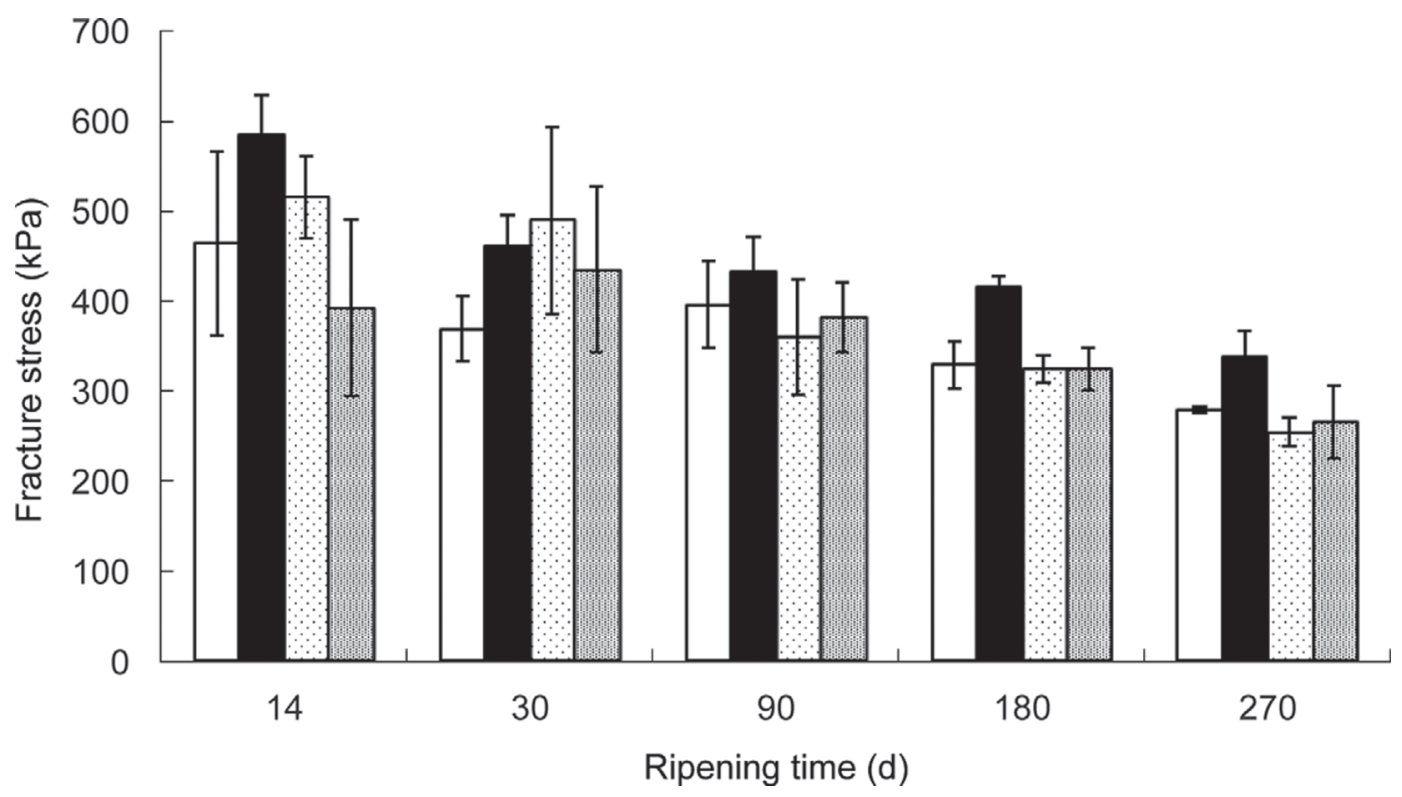

Figure 5. Age-related changes in fracture stress in control, nonwashed curd cheese with standard (SCaNW, white bar) or reduced-calcium (RCaNW, dotted bar) content, and washed-curd cheese with standard (SCaW, black bar) or reduced-calcium (RCaW, gray bar) content. Presented values are the means of 3 replicate trials; error bars represent standard deviations of the mean.

of colloidal calcium and phosphate to soluble calcium and phosphate, as well as a higher degree of calcium phosphate-mediated protein aggregation and contraction, and is therefore likely to favor a less continuous microstructure (Visser, 1991; Guinee et al., 2000a).

\section{Cheese Color}

Color of cheese, as defined by $\mathrm{L}^{*}$ (whiteness), $\mathrm{a}^{*}$ (redness), and $\mathrm{b}^{*}$ (yellowness) or the hue angle, was not affected by curd washing or by calcium content of the cheese (data not shown). Similarly, ripening time did not affect the whiteness of any of the cheeses, but significantly increased the redness and reduced the yellowness in all cheeses. These changes coincided with a reduction in moisture content and $\mathrm{pH}$, and an increase in levels of fat and NPN (percent of total N). Regression analysis of the data (from all ripening times) indicated that levels of both $\mathrm{pH} 4.6-\mathrm{SN}$ and FAA were positively correlated with $\mathrm{a}^{*}(\mathrm{df}=14 ; \mathrm{r}=0.63$ and 0.58 , respectively) and negatively with $\mathrm{b}^{*}(\mathrm{df}=14 ; \mathrm{r}$ $=0.56$ and 0.56 ).

\section{Volatile Compounds Analysis}

Volatile compounds are associated with different odors (Singh et al., 2003) and contribute to cheese flavor to an extent dependent on the concentration and the relative proportions of volatile compounds and nonvolatile taste compounds present in the cheese, as well as the properties of the cheese matrix (Le Quéré et al., 1998). In the current study, over 40 compounds typical of those found in Cheddar cheese (Singh et al., 2003; Carunchia Whetstine et al., 2007) were identified in the 270-d-old cheeses. Thirty-four major compounds, consisting of 10 alcohols, 6 ketones, 4 esters, 6 aldehydes, 5 acids, and 3 sulfur compounds, were identified in all of the cheeses.

The PCA was undertaken to establish if the different cheeses could be separated by the types and concentrations of volatile compounds; a biplot of the scores of the cheeses and the loadings of the attributes is presented in Figure 6. Principal components PC1 and PC2 accounted for 39 of and $36 \%$ of explained variance between the cheeses, respectively. The PC1 separated the cheeses on the basis of calcium content, with SCa cheeses scoring negatively and the RCa cheeses scoring positively. The PC2 separated the cheeses on the basis of the wash treatment, with nonwashed cheeses scoring higher than the washed-curd cheeses. The SCaNW and SCaW cheeses scored negatively on PC1 and PC2 and had significantly lower concentrations of total aroma compounds than the corresponding RCaNW and RCaW cheeses.

The PCA biplot shows that SCaNW and SCaW cheeses grouped together and were associated with volatiles such as dimethyl disulfide, 2-butanone, 2-propanol, 2-methyl-propanal, and ethyl acetate. The latter compounds are associated with etheric, pungent, malt, and fruity-sweet odors in Cheddar cheese (Singh et al., 


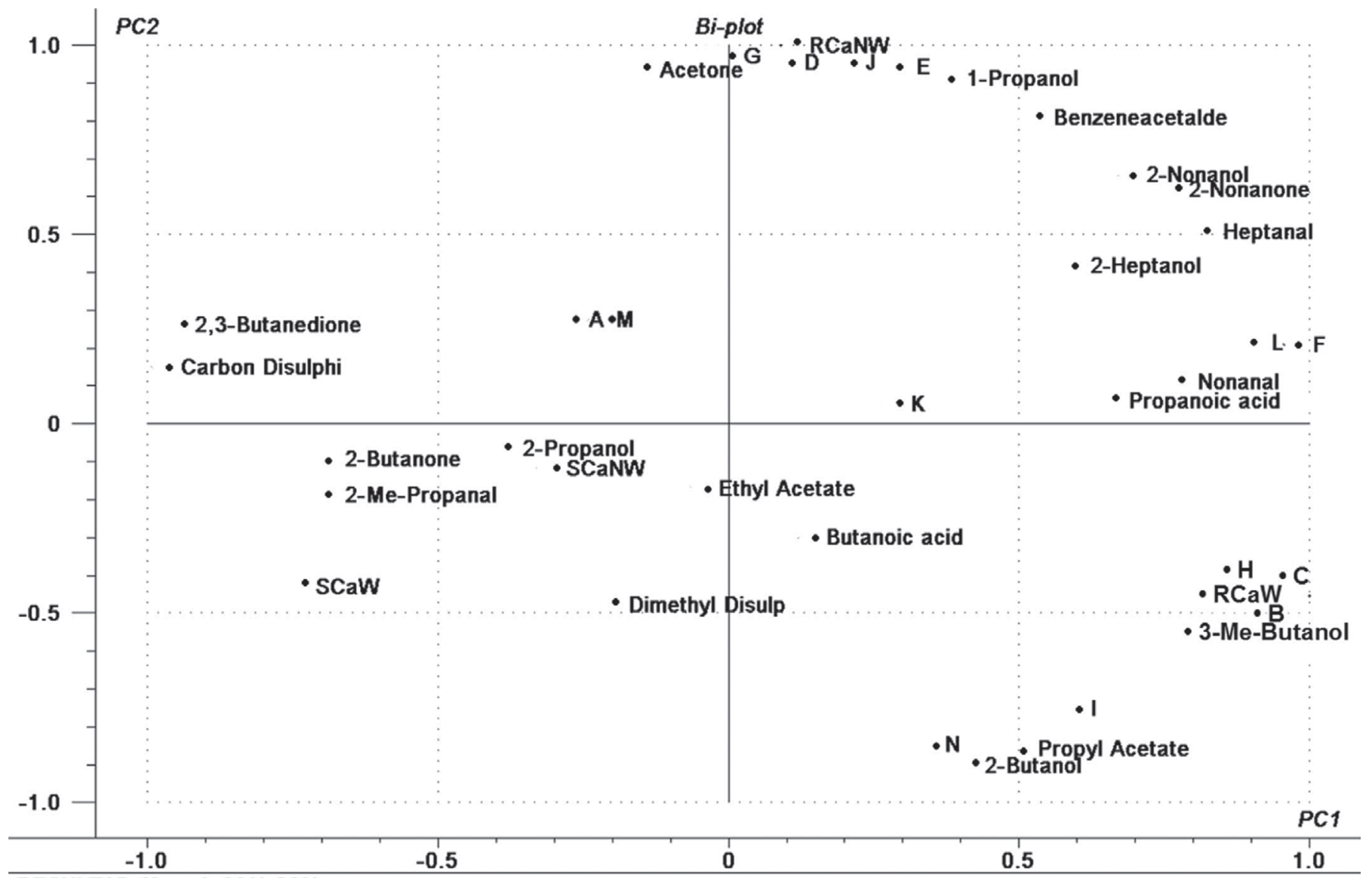

RESULT15, X-expl: 39\%,36\%

Figure 6. Principal component analysis showing the first 2 principal components (PC) of volatile compounds in 270-d-old control, nonwashed curd cheese with standard (SCaNW) or reduced-calcium (RCaNW) content and washed-curd cheese with standard (SCaW) or reduced-calcium $(\mathrm{RCaW})$ content. Presented values are the means of the 3 replicate trials. The names of some volatile compounds that were overlapping in the PCA plot are abbreviated as follows to facilitate viewing: $\mathrm{A}=1$-pentanol; $\mathrm{B}=\mathrm{Me}-1$-butanol; $\mathrm{C}=2$-Me-1-propanol; $\mathrm{D}=2,3$-butanediol; $\mathrm{E}=$ ethanol; $\mathrm{F}=2$-heptanone; $\mathrm{G}=2$-pentanone; $\mathrm{H}=$ hexanoic acid, ethyl ester; $\mathrm{I}=$ octanoic acid, ethyl ester; $\mathrm{J}=$ acetic acid; $\mathrm{K}=$ hexanoic acid; $\mathrm{L}=$ octannic acid; $\mathrm{M}=$ methanethiol; $\mathrm{N}=2$-butanal.

2003) and are likely to have contributed to the fruity and pungent flavor identified on sensory analysis of the SCaNW and SCaW cheeses (Figure 6). The RCaNW cheese were discriminated as a group, and were more associated with alcohols (1-propanol, 2-nonanol, 2-heptanol), ketones (nonanal, heptanal, 2-pentanal), and acids (propa-, octa-, and hexanoic acids; Figure 6). These compounds were associated with fruity, pungent, waxy sensory attributes. The RCaW cheese separated as a third grouping and was characterized by volatiles such as 3-methyl-butanal, 2-methyl-1-propanol, and 3-methyl-1-butanol, and by flavor attributes including onion, pungent, and rancid.

\section{Descriptive Sensory Analysis}

The PCA plot for the different odor and flavor attributes of the 270-d-old cheeses is shown in Figure
7. The first $2 \mathrm{PC}$ discriminated significantly between the cheeses and accounted for a cumulative explained variance of $80 \%$. Both PC1 (46\% of explained variance) and PC2 (34\% of explained variance) separated the cheeses on the basis of the calcium content, with the SCaNW and SCaW cheeses scoring negatively and the RCa cheeses scoring positively across PC2. The cheeses were classified into 3 major groupings by $\mathrm{PC} 1$ and PC2: RCaNW and RCaW, SCaNW, and SCaW. The RCaNW and RCaW cheeses had flavors described as pungent, onion, rancid, buttery, and caramel, odors as caramel and buttery, and a taste as bitter; however, compared with the RCaNW cheese, the flavor and odor of the RCaW cheese was slightly more buttery and caramel. These attributes are consistent with the presence of various volatile compounds [Singh et al., 2003; e.g., pungent (2-butanol, 2-pentanol, 1-propanol) and bitter (benzaldehyde, 2-hexenal)] in the RCaNW and 


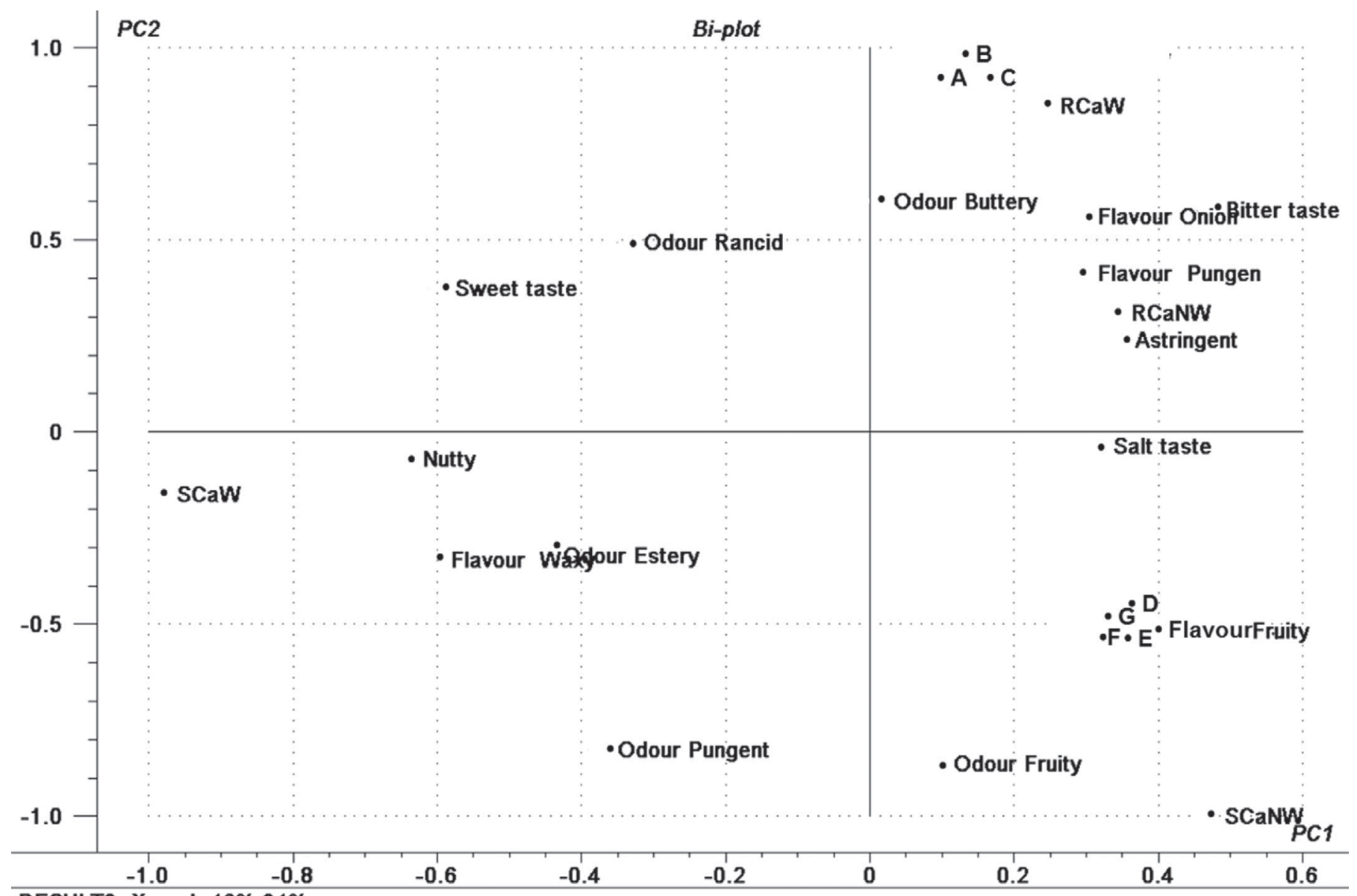

RESULT3, X-expl: $46 \%, 34 \%$

Figure 7. Principal component analysis showing the first 2 principal components (PC) of descriptive sensory odor and flavor attributes in 270-d-old control, nonwashed curd cheese with standard (SCaNW) or reduced-calcium (RCaNW) content, and washed-curd cheese with standard $(\mathrm{SCaW})$ or reduced-calcium $(\mathrm{RCaW})$ content. Presented values are the means of the 3 replicate trials. Abbreviations: $\mathrm{A}=$ flavor caramel; $\mathrm{B}=$ odor caramel; $\mathrm{C}=$ flavor buttery; $\mathrm{D}=$ odor sweaty/cheesy; $\mathrm{E}=$ acid taste; $\mathrm{F}=$ flavor rancid; $\mathrm{G}=$ flavor sweaty $/$ cheesy.

RCaW cheeses. The SCaNW cheeses had flavor and odor described as sweaty, cheesy, fruity, and a taste as salty and acid. The SCaW cheeses had a waxy flavor, a pungent, estery odor, and a sweet nutty taste. The fruity and pungent odor perceived in both the SCaNW and $\mathrm{SCaW}$ cheeses is consistent with the presence of 2-propanol and ethyl acetate in their volatile fractions (Figure 7). Nevertheless, the fact that the SCaW and SCaNW belong to the same PCA grouping for volatile compounds (Figure 6), but a different grouping for the corresponding descriptive sensory analyses (Figure 7), confirms that sensory perception of cheese at any time is complex, being determined by volatile compounds, taste compounds, texture, and their interaction (Szczesniak, 2002).

The results demonstrated that curd washing differentiated the sensory characteristics of the 270-d-old SCaNW and SCaW cheeses, with the latter cheese having a waxier flavor, a more estery, less fruity, less sweaty cheesy odor, and nuttier and sweeter taste than the SCaNW cheeses. This finding concurs with previous studies (Shakeel-Ur-Rehman et al., 2004; Hou et al., 2014), which found that washed-curd cheeses had a significantly lower intensity of unclean and acid tastes than the corresponding cheeses from control or lactosefortified milk, probably as a consequence of the lower levels of lactic acid and higher $\mathrm{pH}$ of the washed-curd cheeses. In contrast, curd washing was not as effective in discriminating between RCaW and RCaNW cheeses. The discrepancy in the effect of curd washing between the SCaNW and SCaW cheeses and RCaNW and RCaW cheeses may be due to the smaller differences in lactic acid and $\mathrm{pH}$ between the RCaNW and $\mathrm{RCaW}$ cheeses compared with the SCaNW and SCaW cheeses.

Reducing the calcium content discriminated between the washed cheeses (SCaW, RCaW), and to a lesser extent between the nonwashed cheeses (SCaNW, RCaNW). The RCaW cheeses had a more buttery, 
Table 4. Biochemical parameters of 270-d-old, control nonwashed, and washed-curd Cheddar cheeses with standard- or reduced-calcium levels ${ }^{1,2}$

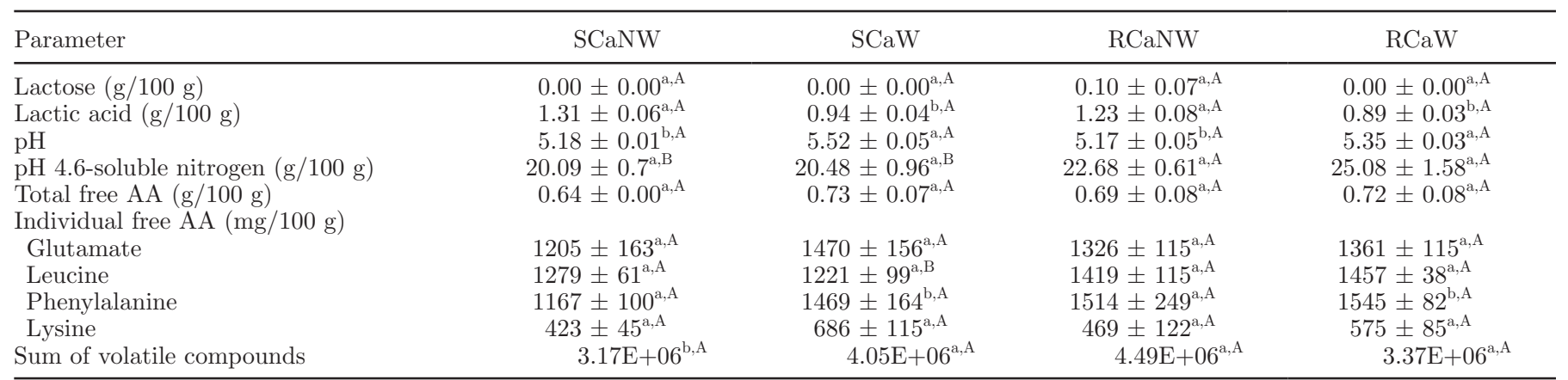

a,b Values not sharing a common lowercase superscript differ significantly for the statistical effect of washing on the standard calcium (SCaNW, $\mathrm{SCaW})$ and on the reduced-calcium $(\mathrm{RCaNW}, \mathrm{RCaW})$ cheeses $(P<0.05)$.

${ }^{\mathrm{A}, \mathrm{B}}$ Values not sharing a common uppercase superscript differ significantly for the effect of reducing calcium on the nonwashed (SCaNW, $\mathrm{RCaNW})$ and washed $(\mathrm{SCaW}, \mathrm{RCaW})$ cheeses $(P<0.05)$.

${ }^{1}$ The cheese treatments, described in detail in Materials and Methods, included control, nonwashed curd cheeses with standard (SCaNW) or reduced-calcium $(\mathrm{RCaNW})$ content, and washed-curd cheese with standard (SCaW) or reduced-calcium (RCaW) content.

${ }^{2}$ ANOVA was used to determine differences between treatments.

caramel odor and flavor, and a more bitter, less sweet and nutty taste than the SCaW cheeses. This trend is consistent with the lower $\mathrm{pH}$ of the $\mathrm{RCaW}$ cheese, which would favor a lower degree of dissociation of acids, such as lactic, glutamic, and aspartic to the salt forms, and a corresponding increase in the intensity of acid flavor (Table 4; Neta et al., 2009). Moreover, the higher level of primary proteolysis in RCaW at $270 \mathrm{~d}$, as indicated by the higher level of $\mathrm{pH} 4.6-\mathrm{SN}$ (Figure 4a), could also be a contributory factor to its more bitter flavor. Analysis of variance of PTA-SN and FAA nitrogen, as percentages of $\mathrm{pH} 4.6 \mathrm{SN}$, in the 270-d-old cheeses indicated no difference between the mean values for the $\mathrm{RCaW}$ and $\mathrm{SCaW}$ cheeses (data not shown), suggesting a possible greater accumulation of medium- to low-molecular weight bitter peptides in the RCaW cheese (Stadhouders and Hup, 1975; Visser, 1977; Exterkate et al., 1995). The RCaNW cheese had a more pungent and less fruity flavor, a less fruity odor, a saltier, more bitter and less acid taste, and a more astringent mouthfeel than the SCaNW cheese. This may reflect the nonsignificant higher concentration of glutamate, leucine, phenylalanine, and lysine, which contribute to acid, bitter, and umami flavors (Solms, 1969; Nishimura and Kato, 1988), in the RCaNW cheese.

\section{CONCLUSIONS}

Cheddar cheeses were manufactured with standard $(\sim 762 \mathrm{mg} / 100 \mathrm{~g})$ or reduced calcium ( $\sim 654$ or 675 $\mathrm{mg} / 100 \mathrm{~g}$ ) levels. Curd washing was used to vary the levels of LLAMc in the SCa and RCa cheeses from $\sim 5.3$ to $3.9 \mathrm{~g} / 100 \mathrm{~g}$ of moisture. Curd washing significantly reduced the mean concentration of lactic acid and in- creased the mean values of $\mathrm{pH}$ and fracture stress of the SCaW cheese over the 270-d ripening period, but did not affect these parameters in the $\mathrm{RCaW}$ cheese. Nevertheless, curd washing significantly reduced the lactic acid content and increased the $\mathrm{pH}$ of the $\mathrm{RCa}$ cheese at $270 \mathrm{~d}$ (though not at other ripening times). The 270-d-old RCaW cheese had more buttery and caramel flavor than the corresponding RCaNW cheese, whereas the SCaW cheese had a waxier flavor, a more estery, less fruity, less sweaty cheesy odor, and nuttier and sweeter taste than the corresponding SCaNW cheese. Otherwise, curd washing did not significantly affect gross composition, microbiology, proteolysis, or color. Reducing the calcium level in the cheese significantly increased the levels of $\mathrm{pH} 4.6$-SN at most ripening times in the nonwashed cheese ( $\mathrm{RCaNW})$, but only at $\mathrm{d} 270$ in the washed-curd cheese (RCaW). Descriptive sensory analysis of the 270-d-old cheeses indicated that RCaNW and RCaW cheeses had more pungent, onion, rancid, buttery, and caramel flavors, more caramel and buttery odors, and a more bitter taste than the corresponding SCaNW and SCaW cheeses. This study demonstrated that nonwashed Cheddar cheeses with relatively low calcium levels $(\sim 664 \mathrm{mg} / 100 \mathrm{~g})$ had significant quantities of residual lactose, even after advanced ripening times of 180 to $270 \mathrm{~d}$. The higher residual lactose levels in the RCaNW cheeses coincided with a nonsignificant higher level of salt-in-moisture, possibly because of a structural alteration to the curd at salting which enhanced salt uptake. Residual lactose may be undesirable to those predisposed to galactosemia (lactose intolerance), which is a metabolic disorder and affects large regions of the world population. The exclusion of cheese (a high-protein, calcium-rich food) from the diet of such populations could have nutri- 
tional and economic consequences. The current study, however, showed that curd washing is a very effective means of reducing and controlling the levels of residual lactose in Cheddar cheeses with different calcium levels. Apart from the latter effect, curd washing is an effective tool to differentiate the sensory properties of aged (270-d-old) Cheddar cheese to an extent that varies with calcium content.

\section{ACKNOWLEDGMENTS}

This work was funded by the Department of Agriculture, Fisheries and Food (Dublin, Ireland), under the National Development Plan and Food Institutional Research Measure with project reference no. 08RDC604.

\section{REFERENCES}

Carunchia Whetstine, M. E., P. J. Luck, M. A. Drake, E. A. Foegeding, P. D. Gerard, and D. M. Barbano. 2007. Characterization of flavor and texture development within large $(291 \mathrm{~kg})$ blocks of Cheddar cheese. J. Dairy Sci. 90:3091-3109.

CFR. 2008. Code of Federal Regulations Part 133. Cheese and related products. Food and Drugs 21 - Code of Federal Regulations, Parts 100-169. US Government Printing Office, Washington, DC. Accessed Feb. 14, 2014. http://www.accessdata.fda.gov/scripts/ cdrh/cfdocs/cfcfr/CFRSearch.cfm?CFRPart $=133$.

Coolbear, T., J. R. Reid, and G. G. Pritchard. 1992. Stability and specificity of the cell wall-associated proteinase from Lactococcus lactis ssp. cremoris $\mathrm{H} 2$ released by treatment with lysozyme in the presence of calcium ions. Appl. Environ. Microbiol. 58:3263-3270.

Czulak, J., J. Conochie, B. J. Sutherland, and H. J. M. van Leeuwen. 1969. Lactose, lactic acid and mineral equilibria in Cheddar cheese manufacture. J. Dairy Res. 36:93-101.

Exterkate, F. A., and A. C. Alting. 1999. Role of calcium in activity and stability of the Lactococcus lactis cell envelope proteinase. Appl. Environ. Microbiol. 65:1390-1396.

Exterkate, F. A., A. C. Alting, and C. J. Slangen. 1995. Conversion of as1-casein-(24-199)-fragment and $\beta$-casein under cheese conditions by chymosin and starter peptidases. Syst. Appl. Microbiol. $18: 7-12$.

Fenelon, M. A., T. P. Guinee, C. Delahunty, J. Murray, and F. Crowe. 2000a. Composition and sensory attributes of retail Cheddar cheese with different fat contents. J. Food Compos. Anal. 13:13-26.

Fenelon, M. A., P. O'Connor, and T. P. Guinee. 2000b. The effect of fat content on the microbiology and proteolysis in Cheddar cheese during ripening. J. Dairy Sci. 83:2173-2183.

Fenelon, M. A., P. O'Connor, and T. P. Guinee. 2000c. The effect of fat content on the microbiology and proteolysis in Cheddar cheese during ripening. J. Dairy Sci. 83:2173-2183.

Fox, P. 1970. Influence of aggregation on the susceptibility of casein to proteolysis. J. Dairy Res. 37:173-180.

Fox, P. F. 2000. Fundamentals of Cheese Science. Aspen Publisher Inc., Gaithersburg, MD.

Fox, P. F., and T. P. Guinee. 2013. Cheese science and technology. Pages 357-389 in Milk and Dairy Products in Human Nutrition: Production, Composition and Health. John Wiley \& Sons, Oxford, UK.

Gilles, J. 1976. Control of salt on moisture levels in Cheddar cheese. N.Z. J. Dairy Sci. Tech. 11:219-221.

Guinee, T. 2003. Role of protein in cheese and cheese products. Pages 1083-1174 in Advanced Dairy Chemistry - 1 Proteins. Kluwer Academic/Plenum Publishers, New York, NY.

Guinee, T., and B. Sutherland. 2011. Salting of Cheese. Academic Press, London, UK.
Guinee, T. P., M. A. E. Auty, and M. A. Fenelon. 2000a. The effect of fat content on the rheology, microstructure and heat-induced functional characteristics of Cheddar cheese. Int. Dairy J. 10:277-288.

Guinee, T. P., E. P. Feeney, M. A. E. Auty, and P. F. Fox. 2002. Effect of $\mathrm{pH}$ and calcium concentration on some textural and functional properties of Mozzarella cheese. J. Dairy Sci. 85:1655-1669.

Guinee, T. P., D. Harrington, M. O. Corcoran, E. O. Mulholland, and C. Mujllins. 2000b. The compositional and functional properties of commercial Mozzarella, Cheddar and analogue pizza cheeses. Int. J. Dairy Technol. 53:51-56.

Guinee, T. P., K. N. Kilcawley, and T. P. Beresford. 2008. How variable are retail vintage brands of Cheddar cheese in composition and biochemistry? Aust. J. Dairy Technol. 63:50-60.

Hannon, J. A., K. N. Kilcawley, M. G. Wilkinson, C. M. Delahunty, and T. P. Beresford. 2007. Flavour precursor development in Cheddar cheese due to lactococcal starters and the presence and lysis of Lactobacillus helveticus. Int. Dairy J. 17:316-327.

Hooydonk, A. v., H. Hagedoorn, and I. Boerrigter. 1986. pH-induced physico-chemical changes of casein micelles in milk and their effect on renneting. 1. Effect of acidification on physico-chemical properties. Neth. Milk Dairy J. 40:281-296.

Hou, J., J. A. Hannon, P. L. H. McSweeney, T. P. Beresford, and T. P. Guinee. 2012. Effect of curd washing on composition, lactose metabolism, $\mathrm{pH}$, and the growth of non-starter lactic acid bacteria in full-fat Cheddar cheese. Int. Dairy J. 25:21-28.

Hou, J., J. A. Hannon, P. L. H. McSweeney, T. P. Beresford, and T. P. Guinee. 2014. Effect of curd washing on cheese proteolysis, texture, volatile compounds, and sensory grading in full fat Cheddar cheese. Int. Dairy J. 34:190-198.

Jarrett, W. D., J. W. Aston, and J. R. Dulley. 1982. A simple method for estimating free amino acids in cheddar cheese. Aust. J. Dairy Technol. 37:55-58.

Jordan, K. N., and T. M. Cogan. 1993. Identification and growth of non-starter lactic acid bacteria in Irish Cheddar cheese. Ir. J. Agric. Food Res. 32:47-55.

Kosikowski, F., and P. Fox. 1968. Low heat, hydrogen peroxide, and bactofugation treatments of milk to control coliforms in Cheddar cheese. J. Dairy Sci. 51:1018-1022.

Lawrence, R. C., L. K. Creamer, and J. Gilles. 1986. Texture development during cheese ripening. J. Dairy Sci. 70:1748-1760.

Lawrence, R. C., H. A. Heap, and J. Gilles. 1984. A controlled approach to cheese technology. J. Dairy Sci. 67:1632-1645.

Le Quéré, J.-L., A. Pierre, A. Riaublanc, and D. Demaizières. 1998. Characterization of aroma compounds in the volatile fraction of soft goat cheese during ripening. Lait 78:279-290.

Lee, M.-R., M. E. Johnson, S. Govindasamy-Lucey, J. J. Jaeggi, and J. A. Lucey. 2011. Effect of different curd-washing methods on the insoluble Ca content and rheological properties of Colby cheese during ripening. J. Dairy Sci. 94:2692-2700.

Lucey, J. A., and P. F. Fox. 1993. Importance of calcium and phosphate in cheese manufacture: A review. J. Dairy Sci. 76:1714-1724.

Mulvihill, D., and P. Fox. 1977. Proteolysis of asl-casein by chymosin: Influence of $\mathrm{pH}$ and urea. J. Dairy Res. 44:40.

Neta, E. R., S. Johanningsmeier, M. Drake, and R. McFeeters. 2009 Effects of $\mathrm{pH}$ adjustment and sodium ions on sour taste intensity of organic acids. J. Food Sci. 74:S165-S169.

Nishimura, T., and H. Kato. 1988. Taste of free amino acids and peptides. Food Rev. Int. 4:175-194.

O'Brien, B., R. Mehra, J. F. Connolly, and D. Harrington. 1999. Seasonal variation in the composition of Irish manufacturing and retail milks: 1. Chemical composition and renneting properties. Ir. J. Agric. Food Res. 38:53-64.

O'Keeffe, R., P. Fox, and C. Daly. 1975. Proteolysis in Cheddar cheese: Influence of the rate of acid production during manufacture. J. Dairy Res. 42:111-122.

O'Mahony, J. A., J. A. Lucey, and P. L. H. McSweeney. 2005. Chymosin-mediated proteolysis, calcium solubilization, and texture development during the ripening of Cheddar cheese. J. Dairy Sci. 88:3101-3114.

Rea, M. C., C. Franz, W. Holzapfel, and T. Cogan. 2004. Development of enterococci and production of tyramine during the manu- 
facture and ripening of Cheddar cheese. Ir. J. Agric. Food Res. $43: 247-258$.

Salaün, F., B. Mietton, and F. Gaucheron. 2005. Buffering capacity of dairy products. Int. Dairy J. 15:95-109.

SAS Institute. 2004. SAS User's Guide: Statistics. Version 9.12 ed. SAS Institute Inc., Cary, NC.

Shakeel-Ur-Rehman, , D. Waldron, and P. F. Fox. 2004. Effect of modifying lactose concentration in cheese curd on proteolysis and in quality of Cheddar cheese. Int. Dairy J. 14:591-597.

Sheehan, A., G. O. Cuinn, R. J. FitzGerald, and M. G. Wilkinson. 2006. Proteolytic enzyme activities in Cheddar cheese juice made using lactococcal starters of differing autolytic properties. J. Appl. Microbiol. 100:893-901.

Singh, T. K., M. A. Drake, and K. R. Cadwallader. 2003. Flavor of Cheddar cheese: A chemical and sensory perspective. Compr. Rev. Food Sci. Food Saf. 2:166-189.

Solms, J. 1969. Taste of amino acids, peptides, and proteins. Int. Z Vitaminforsch. 39:320-322.

Stadhouders, J., and G. Hup. 1975. Factors affecting bitter flavour in Gouda cheese. Neth. Milk Dairy J. 29:335-353.

Szczesniak, A. S. 2002. Texture is a sensory property. Food Qual Prefer. 13:215-225.

Thomas, T. D., and K. N. Pearce. 1981. Influence of salt on lactose fermentation and proteolysis in Cheddar cheese. N.Z. J. Dairy Sci. Tech. 16:253-259.

Turner, K. W., and T. D. Thomas. 1980. Lactose fermentation in Cheddar cheese and the effect of salt. N.Z. J. Dairy Sci. Tech. 15:265-276.
Upreti, P., and L. E. Metzger. 2006a. Influence of calcium and phosphorus, lactose, and salt-to-moisture ratio on Cheddar cheese quality: manufacture and composition. J. Dairy Sci. 89:420-428.

Upreti, P., and L. E. Metzger. 2007. Influence of calcium and phosphorus, lactose, and salt-to-moisture ratio on Cheddar cheese quality: $\mathrm{pH}$ changes during ripening. J. Dairy Sci. 90:1-12.

Upreti, P., L. E. Metzger, and K. D. Hayes. 2006b. Influence of calcium and phosphorus, lactose, and salt-to-moisture ratio on Cheddar cheese quality: Proteolysis during ripening. J. Dairy Sci. 89:444-453.

Visser, F. 1977. Contribution of enzymes from rennet, starter bacteria and milk to proteolysis and flavour development in Gouda cheese. 2. Development of bitterness and cheese flavour. Neth. Milk Dairy J. 31:188-209.

Visser, J. 1991. Factors affecting the rheological and fracture properties of hard and semi-hard cheese. Pages 49-61 in IDF Bull. 268. International Dairy Federation, Brussels, Belgium.

White, J., and D. Davies. 1958. The relation between the chemical composition of milk and the stability of the caseinate complex: I. General introduction, description of samples, methods and chemical composition of samples. J. Dairy Res. 25:236-255.

Zeppa, G., L. Conterno, and V. Gerbi. 2001. Determination of organic acids, sugars, diacetyl, and acetoin in cheese by high-performance liquid chromatography. J. Agric. Food Chem. 49:2722-2726. 